\title{
Simulação com painéis de fibra de açaí para melhoria da inteligibilidade da fala em sala de aula
}

\author{
Simulation with açaí fiber panels for improving speech \\ intelligibility in classroom
}

\section{Leopoldo Pacheco Bastos \\ Lays da Cunha Lima \\ Gabriel Brandão Santos \\ Gustavo da Silva Vieira de Melo Alexandre Luiz Amarante Mesquita}

\section{Resumo}

${ }^{1}$ Leopoldo Pacheco Bastos 'Universidade Federal do Pará Tucuruí - PA - Brasil

${ }^{2}$ Lays da Cunha Lima ${ }^{2}$ Universidade Federal do Pará Belém - PA - Brasil

${ }^{3}$ Gabriel Brandão Santos ${ }^{3}$ Universidade Federal do Pará Belém - PA - Brasil

${ }^{4}$ Gustavo da Silva Vieira de Melo ${ }^{4}$ Universidade Federal do Pará Belém - PA - Brasil

${ }^{5}$ Alexandre Luiz Amarante Mesquita

5Universidade Federal do Pará Belém - PA - Brasil

Recebido em 31/08/20 Aceito em 08/12/20
A

inteligibilidade da fala dos professores em sala de aula e o aprendizado dos alunos são comprometidos pelos níveis de ruído ambiente e excesso de reverberação, causando falta de concentração, fadiga e estresse. A necessidade de uma apropriada condição acústica em sala de aula, quando a voz é a fonte sonora principal, foi o que motivou este estudo. Buscando solução baseada em absorvedores acústicos ambientalmente sustentáveis, este artigo investiga aplicações acústicas da fibra do caroço de açaí, uma fibra vegetal abundante na região Amazônica. Inicialmente foram feitas medições de parâmetros acústicos (tempo de reverberação, tempo de decaimento inicial, clareza, definição e éndice rápido de transmissão da fala) em uma sala de aula e em seguida foi desenvolvido um modelo numérico acústico da sala. Após a validação do modelo, várias configurações de disposição de painéis absorvedores feitos com fibra de açaí foram analisadas no modelo para verificar a influência na qualidade acústica da sala de aula investigada. Os resultados das simulações indicam que os painéis de fibra de açaí podem ser uma solução bastante atrativa, aliando baixo custo e bom desempenho.

Palavras-chave: Simulação numérica. Parâmetros acústicos. Fibra de açaí. Inteligibilidade da fala.

\section{Abstract}

Speech intelligibility in classrooms and students' learning capabilities are compromised by ambient noise and excessive reverberation, causing lack of concentration, tiredness and stress. The motivation for this study was the need for appropriate acoustic conditions in classrooms, where speech is the main sound source. In order to find a solution based on environmentally sustainable acoustic absorbers, this paper investigates the acoustical applications of açaí seed fibre, an abundant vegetable fibre in the Amazon region. Initially, measurements of acoustic parameters (Reverberation Time, Initial Decay Time, Clarity, Definition and Rapid Speech Transmission Index) were made in a classroom and then an acoustic numerical model of the room was developed. After validating the model, various configurations of absorber panels made with açai fibre were analysed in the model to verify the influence on the acoustic quality of the investigated classroom. The results of the simulations indicate that açai fibre boards can be a very attractive solution, combining low cost and good performance.

Keywords: Numerical simulation. Acoustic parameters. Açaífibre. Speech intelligibility. 


\section{Introdução}

Instituições de ensino estão envoltas por ruídos gerados tanto internamente quanto externamente (DREOSSI; SANTOS, 2004). Esses ruídos, que compõem o nível de ruído ambiente, podem comprometer a inteligibilidade da fala dos professores, prejudicando o aprendizado dos alunos. No esforço de corrigir a baixa inteligibilidade, a intensidade da voz é aumentada (GONÇALVES; SILVA; COUTINHO, 2009) e problemas podem surgir no aparelho fonador dos docentes (DURUP et al., 2015; RANTALA; SALA, 2007).

Somada aos problemas de ruído ambiente, a baixa qualidade acústica de salas de aula também prejudica a inteligibilidade (RABELO et al., 2014; ESCOBAR; MORILLAS, 2015; MADBOULY et al., 2016). Um ambiente reverberante, que pode ser agradável para música (VERGARA; MORROS; PAUL, 2017), provavelmente não será adequado para uma sala voltada à fala sem uma adequação acústica (LIMA; VERGARA, 2018). Portanto, ambientes internos voltados à fala (auditórios e salas de aula), que não estejam com um campo acústico adequado, devem ser tratados acusticamente.

O tratamento acústico de ambientes reverberantes envolve tradicionalmente o uso de absorvedores acústicos, os quais podem ser do tipo placas ressonadoras (perfuradas ou não), que têm boa absorção em baixas e médias frequências, ou dos tipos porosos ou fibrosos, que são materiais que permitem a entrada de fluxo de ar em seu interior, apresentando boa absorção sonora, principalmente em altas frequências (a partir de 2.000 Hz) (TANG; YAN, 2017). Nesses materiais fibrosos ou porosos, a energia sonora é dissipada por sua transformação em calor pelo atrito das moléculas de ar ao se movimentarem no interior do material (GERGES, 2000; BISTAFA, 2011). Exemplos de materiais fibrosos são as lãs minerais sintéticas, tais como lã de rocha e lã de vidro.

Apesar de possuírem baixo custo, as lãs minerais possuem as desvantagens de poderem trazer danos à saúde durante o manuseio, desde irritação da pele como problemas respiratórios devido à sua inalação (ASDRUBALI et al., 2012). Os materiais porosos, tais como as espumas de poliuretano, possuem um custo de produção maior e um processo produtivo mais agressivo ao meio ambiente devido aos gases tóxicos emitidos, além de demandarem maior consumo de energia e serem baseados em produtos de origem petroquímica (ASDRUBALI; SCHIAVONIL; HOROSHENKOV, 2012; BERARDI; IANNACE, 2015).

Dessa forma, cresce a busca por materiais absorvedores acústicos ambientalmente sustentáveis (green materials). Segundo Asdrubali, Schiavonil e Horoshenkov (2012), um material pode ser considerado sustentável se sua produção permitir que as fontes pelas quais o material foi produzido continuem disponíveis para as gerações futuras e tenham o menor impacto possível sobre a saúde humana e o meio ambiente. Portanto, materiais naturais e recicláveis se enquadram nessa definição. Logo, uma grande atenção tem sido dada à produção de absorvedores acústicos sustentáveis, baseados em fibras vegetais.

Estudos sobre as propriedades físicas (mecânica, térmica e acústica) de fibras vegetais e seus compósitos vêm sendo realizados e mostraram a possibilidade da utilização de fibras vegetais como materiais sonoabsorventes, sendo estas de fácil obtenção na região amazônica, como as fibras de açaí e de coco (VIEIRA, 2008; BASTOS, 2009; BASTOS; MELO; SOEIRO, 2012).

O açaí é uma fruta com muitos benefícios nutricionais e econômicos na Região Norte do Brasil, tornando-se, a partir da descoberta de suas propriedades antioxidantes, um alimento funcional no combate à produção de radicais livres e, por conseguinte, na redução das chances de doenças cardiovasculares, obesidade, catarata, resistência insulínica, doenças neurodegenerativas e declínio cognitivo relacionado à idade (PORTINHO; ZIMMERMANN; BRUCK, 2012; YAMAGUCHI et al., 2015). Esse fruto amazônico também contribui como fonte alimentar às populações ribeirinhas carentes além de proporcionar a estas uma fonte de renda com o comércio do fruto.

Um problema que surge com a comercialização do açaí é o resíduo gerado, ou seja, o problema da destinação dos caroços de açaí, após o beneficiamento do fruto. Algumas soluções têm sido propostas, como, por exemplo: sua utilização como componente na mistura de areia-asfalto com areias de resíduos de construção e demolição para a pavimentação de ruas (SILVA; SILVA; CASTRO, 2016), uso em adubos (WECKNER et al., 2016; CORREA et al., 2019) e uso da cinza do caroço do açaí residual para adição ao concreto (CORDEIRO et al., 2019). Além dessas alternativas, o uso da fibra do caroço para confecção de painéis acústicos sustentáveis, voltados à absorção sonora em ambientes reverberantes, vem também contribuir para a solução do problema do descarte dos resíduos associados ao comércio de açaí.

Nesse contexto, este artigo analisa numérica e experimentalmente a inteligibilidade da fala em uma sala de aula de uma instituição de ensino superior com e sem o uso de painéis absorvedores acústicos fabricados 
com fibra de açaí. A sala de aula analisada é um ambiente em que a fala deve ser privilegiada, de modo que a difusão sonora seja controlada e as reflexões sonoras indesejadas não prejudiquem sua inteligibilidade.

De acordo com a finalidade da sala e baseando-se na norma NBR ISO 3382-2 (ABNT, 2017), foram analisados os seguintes parâmetros para avaliar a qualidade acústica do ambiente: tempo de reverberação $\left(\mathrm{T}_{30}\right)$, tempo de decaimento inicial $(\mathrm{EDT})$, definição $\left(\mathrm{D}_{50}\right)$, clareza $\left(\mathrm{C}_{50}\right)$ e índice rápido de transmissão da fala (RaSTI), para cada banda de frequência de oitava entre $250 \mathrm{~Hz}$ e $4 \mathrm{kHz}$. O software comercial DIRAC 4.0 foi usado para a determinação dos parâmetros acústicos de forma experimental.

Após a determinação experimental dos parâmetros acústicos da sala foi desenvolvido um modelo acústico do ambiente por meio do software ODEON para determinação numérica dos mesmos parâmetros acústicos obtidos experimentalmente. A partir da concordância entre os resultados obtidos experimental e numericamente, comprovada pela curva de calibração dos parâmetros EDT e $\mathrm{D}_{50}$, o modelo numérico passou a representar o ambiente real, possibilitando simulações com painéis absorvedores, objetivando melhorar a qualidade acústica da sala. As propriedades de absorção sonora dos painéis usados nas simulações numéricas foram obtidas experimentalmente em laboratório com uso de câmara reverberante em escala reduzida. Finalmente, cinco diferentes disposições de painéis absorvedores feitos com fibra de açaí foram analisadas no modelo para verificar a influência na qualidade acústica da sala de aula investigada.

\section{Materiais e métodos}

\section{Painéis absorvedores acústicos à base de fibra de açaí}

Após o beneficiamento do fruto açaí (Figura 1a), os caroços são comumente descartados sem a correta destinação (Figura 1b). Portanto, a partir das fibras dos caroços descartados, foram fabricados painéis absorvedores acústicos de forma artesanal para a avaliação de sua utilização.

O processo de manufatura consistiu na execução das seguintes etapas:

(a) obtenção das fibras e remoção de impurezas;

(b) formação das (quatro) camadas de fibras em um molde com uma prensagem inicial (Figura 2);

(c) adição de aglomerante sobre as camadas de fibras até que estas ficassem cobertas pelo material e apresentassem certa adesão inicial para que o painel pudesse ser montado pela sobreposição dessas camadas;

(d) prensagem final das camadas de fibras intercaladas com aglomerantes; $\mathrm{e}$

(e) secagem dos painéis em temperatura ambiente (BASTOS, 2009; BASTOS; MELO; SOEIRO, 2012).

Após a manufatura dos painéis de $30 \mathrm{~mm}$ de espessura, ensaios experimentais foram realizados para caracterizar suas propriedades de absorção acústica, e para verificar se apresentavam bom desempenho também em relação à flamabilidade, ao envelhecimento (comportamento ao calor), ao odor e ao surgimento de fungos (fungabilidade), pois se trata de material orgânico. Nos trabalhos de Bastos (2009) e Bastos, Melo e Soeiro (2012) todos os processos de manufatura e ensaios estão descritos em detalhes.

Figura 1 - Fruto açaí (a) e aroços do fruto açaí (b)

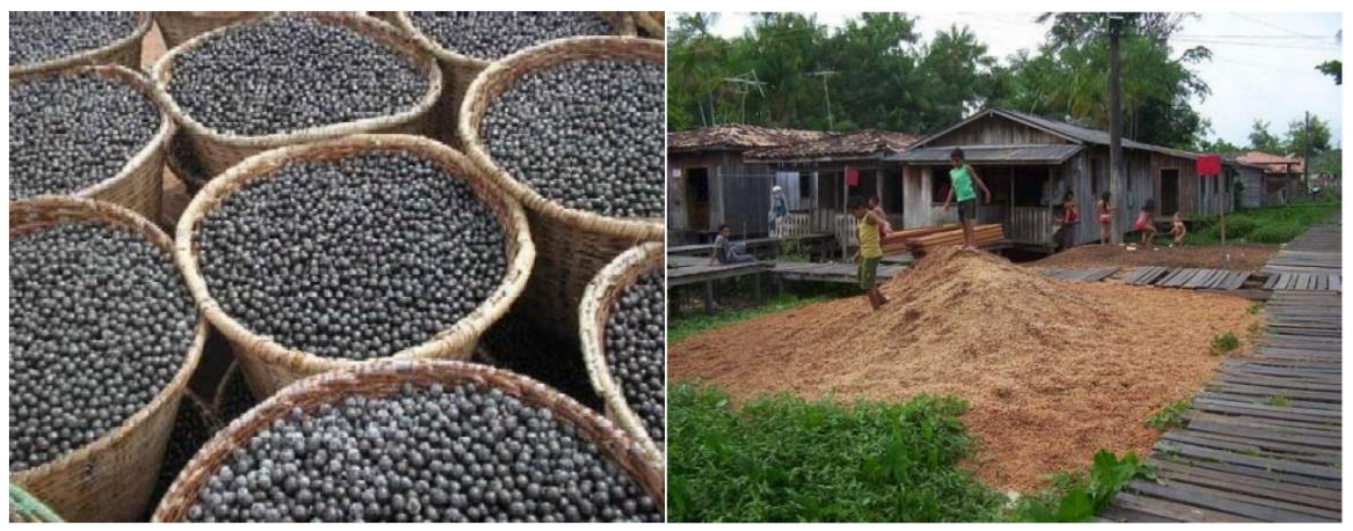

Fonte: Bastos (2009). 
Figura 2 - Formação das camadas de fibras

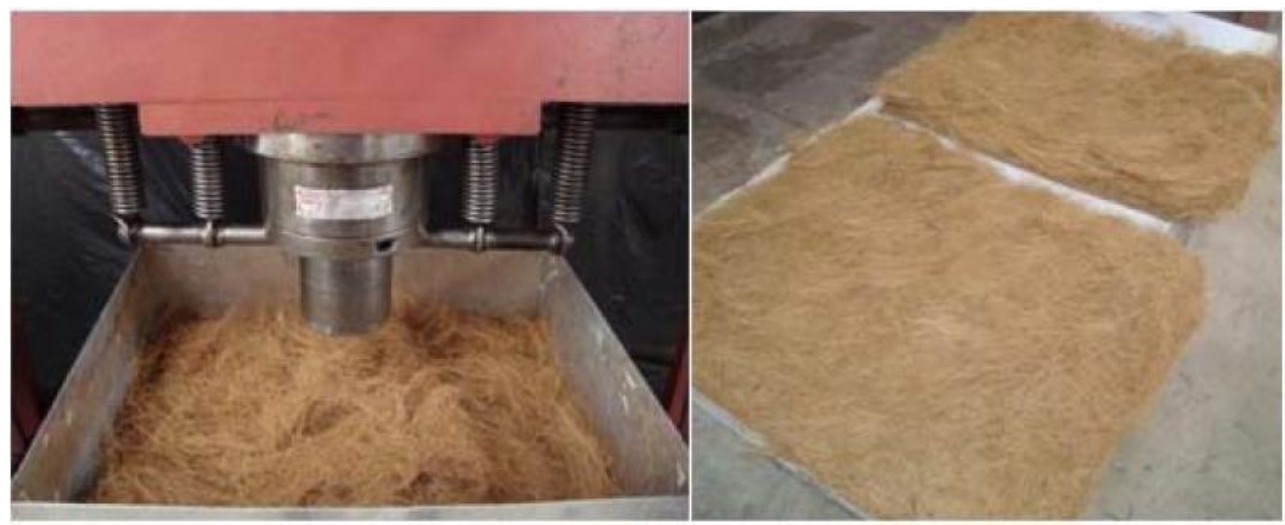

Fonte: Bastos (2009).

\section{Câmara reverberante utilizada}

Para conduzir pesquisas em acústica arquitetônica é necessário dispor de uma sala com características acústicas bem definidas. Em relação a câmaras reverberantes, é importante que estas tenham:

(a) paredes, piso e teto rígidos e altamente refletivos com pequenos coeficientes de absorção sonora;

(b) bom isolamento sonoro, de modo que ruídos externos não interfiram nas medições acústicas; e

(c) campo sonoro suficientemente difuso, pelo menos dentro da faixa de frequência útil, de modo que as curvas de tempo de reverberação correspondentes possam indicar decaimento sonoro adequado, após o desligamento da fonte.

Para cumprir esses requisitos, importantes critérios devem ser levados em consideração, principalmente a seleção das dimensões da câmara, um fator primordial de projeto. Os requisitos relacionados à difusão sonora são mais facilmente alcançados em ambientes com maior volume interno, porém estes exigem maior orçamento e tempo de construção.

A câmara reverberante do Laboratório de Acústica da Universidade Federal do Pará, Campus de Tucuruí, utilizada neste trabalho, foi construída em concreto armado, com paredes de $100 \mathrm{~mm}$ de espessura, e tem aproximadamente $8 \mathrm{~m}^{3}$ de volume interno e dimensões (internas) de 1,60 m de largura, 2,0 $\mathrm{m} \mathrm{de}$ comprimento e $2,5 \mathrm{~m}$ de altura. Essa estrutura fornece isolamento sonoro de aproximadamente $30 \mathrm{~dB}$. Difusores sonoros (volumétricos e suspensos) são empregados para aumentar o grau de difusão sonora em seu interior, conforme ilustrado na Figura 3. Tal comportamento pode ser observado na Figura 4, na qual o pico de energia em $400 \mathrm{~Hz}$ para a condição sem difusores é um modo acústico ressonante da câmara que, em razão da inserção dos difusores, foi dissipado.

Adicionalmente, realizou-se um estudo comparativo para avaliar a concordância dos resultados desta câmara com resultados de uma câmara em escala real. Portanto, ensaios de painéis de fibra de sisal foram realizados na referida câmara em escala e em uma câmara normalizada da Universidade Federal de Santa Maria (UFSM), conforme ilustrado na Figura 5. Os resultados podem ser vistos na Figura 6, na qual se observa boa concordância em tendência e pequena discrepância entre os valores obtidos (máximo de aproximadamente $16 \%$ em $4.000 \mathrm{~Hz}$ ) para as diferentes câmaras.

\section{Método numérico híbrido para acústica de salas}

A caracterização acústica de uma sala ou ambiente envolve o conhecimento das funções de resposta ao impulso do sistema sala-fonte-receptor. Teoricamente, uma função de resposta ao impulso (IRF - Impulse Response Function), também chamada de resposta impulsiva, é uma função temporal da pressão sonora de um ambiente, que resulta da excitação desse espaço por uma função que se aproxima da função delta de Dirac (VORLÄNDER; BIETZ, 1994). Com o conhecimento das IRFs do ambiente, vários parâmetros acústicos podem ser determinados, tais como tempo de reverberação, clareza, índice de transmissão da fala, dentre outros. 
Figura 3 - Exterior e interior da câmara reverberante UFPA-CAMTUC
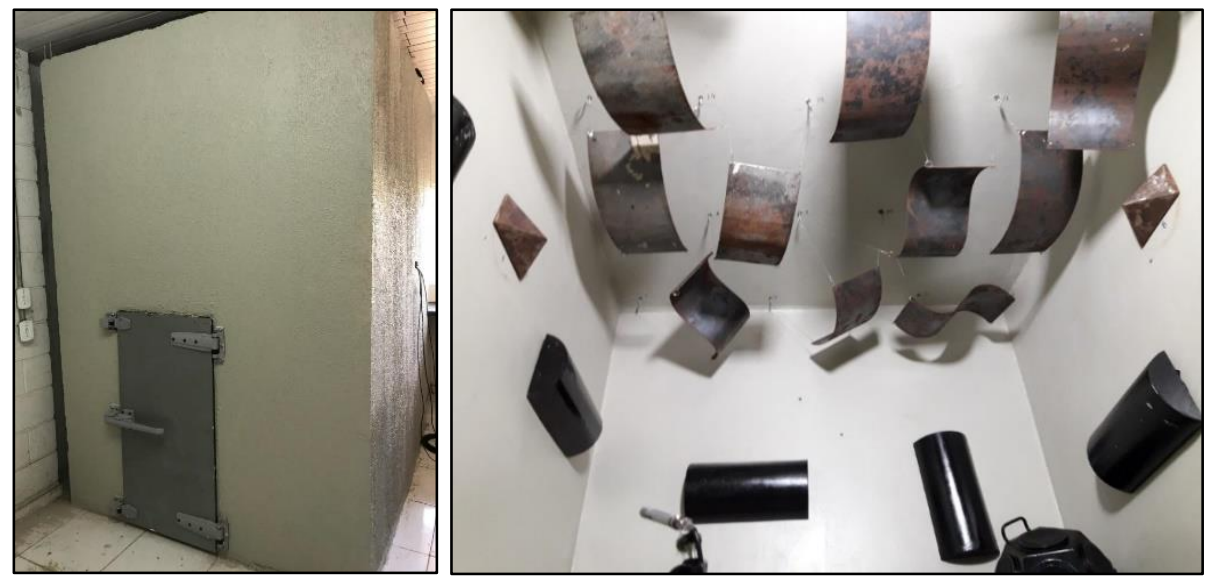

Fonte: Castro e Fonseca (2019).

Figura 4 - Tempos de reverberação com e sem difusores no interior da câmara UFPA-CAMTUC

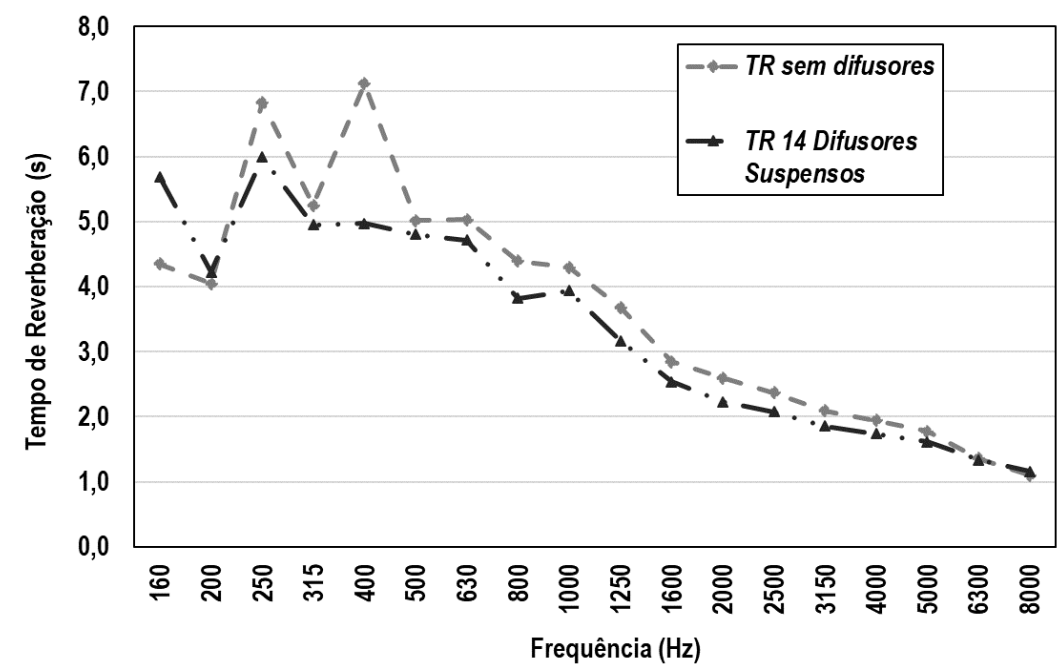

Fonte: Castro e Fonseca (2019).

Figura 5 - Painéis de fibra de sisal sob teste: na câmara em escala da UFPA-CAMTUC (à esquerda) e na câmara normalizada da UFSM (à direita)

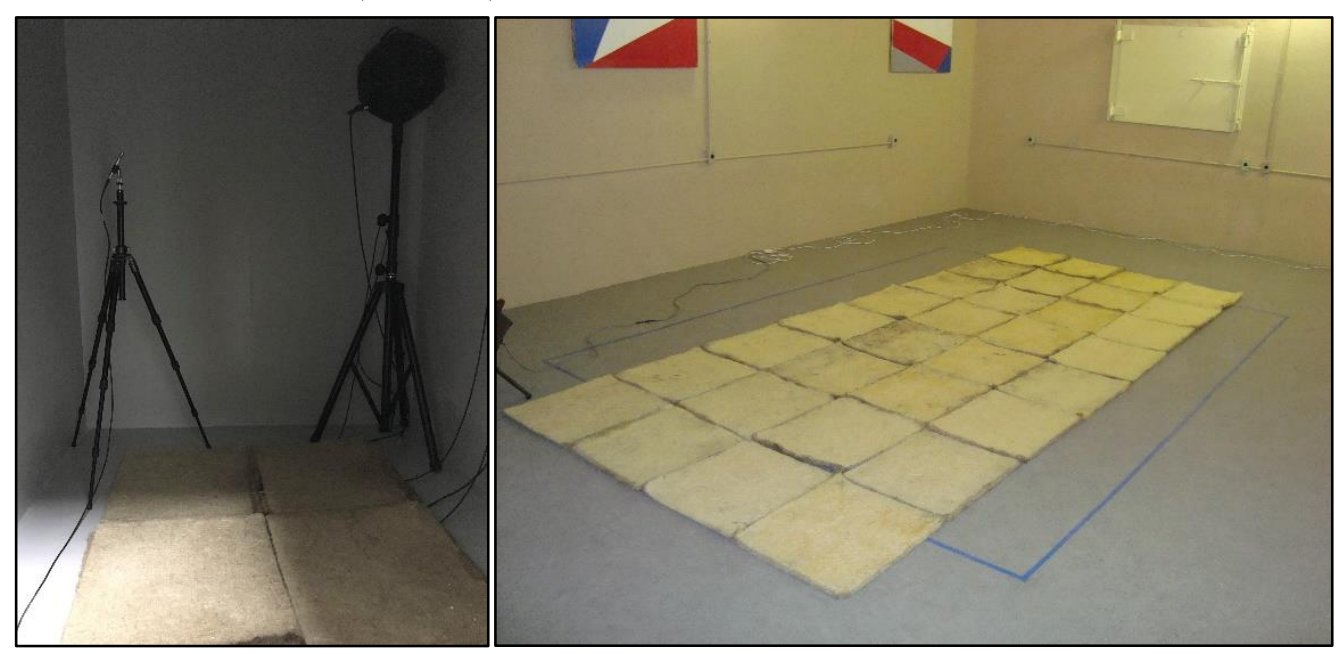


Figura 6 - Comparação dos coeficientes de absorção sonora obtidos para os painéis de fibra de sisal na câmara em escala da UFPA-CAMTUC e na câmara normalizada da UFSM

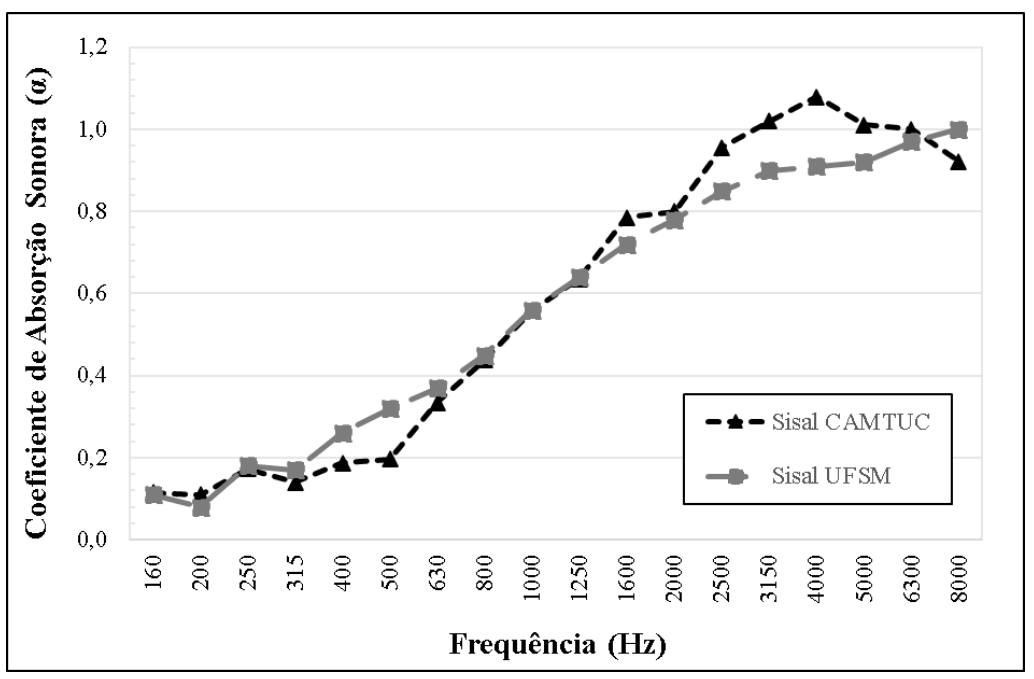

Fonte: Andrade Junior e Guerra (2018).

A determinação das IRFs pode ser realizada por meio de métodos numéricos ou experimentais, apesar de que o modelo numérico sempre irá requerer uma validação experimental. Dentre os métodos numéricos, existem os métodos baseados na resolução da equação da onda e os métodos baseados na propagação geométrica da energia sonora. No primeiro grupo, destacam-se os métodos dos elementos finitos (FEM), dos elementos de contorno (BEM), e das diferenças finitas no domínio do tempo (FDTD). Dentre os métodos da acústica geométrica, destacam-se os métodos do traçado de raios, das fontes virtuais e métodos híbridos, sendo que estes últimos combinam mais de um método da acústica geométrica (BRANDÃO, 2016).

Existem vários softwares dedicados à acústica de salas. Neste artigo utilizou-se o software Odeon Room Acoustics 12.12 Combined, que utiliza uma combinação dos métodos de traçado de raios e de fontes virtuais, que simulam os três fenômenos mais importantes da propagação do som em salas: absorção, reflexão especular e reflexão difusa (TENENBAUM; CAMILO, 2004). Esses algoritmos são desenvolvidos de tal forma que as primeiras reflexões são calculadas a partir da formulação fonte-imagem virtual, e as últimas reflexões são calculadas pela técnica do traçado de raios. Assim, o método híbrido permite maior eficiência na determinação de fontes virtuais e no traçado dos raios das fontes até as superfícies de incidência. Cada trajetória encontrada fica associada a determinadas sequências de fontes virtuais válidas, que são identificadas pela construção do caminho inverso de um raio sonoro. Com as fontes virtuais válidas encontradas, a resposta impulsiva do ambiente pode ser formada pela adição das contribuições de cada fonte e usando os coeficientes de reflexão da energia nas superfícies pertencentes ao ambiente fechado.

\section{Parâmetros acústicos: definições}

A qualidade acústica de uma sala é avaliada a partir de parâmetros objetivos quantificados a partir de medições. Neste artigo foram analisados os seguintes parâmetros:

\section{Tempo de reverberação (TR)}

O tempo de reverberação é definido teoricamente como o tempo necessário para que o nível de pressão sonora, em um ambiente, diminua $60 \mathrm{~dB}$, a partir do estado estacionário, uma vez cessada a fonte de energia sonora. Na sua determinação prática, utiliza-se o tempo de reverberação $T_{30}$, ou seja, o tempo necessário para que o nível de pressão sonora, em um ambiente, diminua $30 \mathrm{~dB}$, a partir do estado estacionário, uma vez cessada a fonte de energia sonora, multiplicado por dois. No Brasil, não existe norma que estabeleça valores ideais para o tempo de reverberação em salas de aula (BERTOLI, 2001). Porém, segundo a parte 1 da norma ANSI/ASA S12.60 (AMERICAN..., 2010), o tempo de reverberação máximo para uma sala de aula com volume menor que $283 \mathrm{~m}^{3}$ deve ser menor que $0,6 \mathrm{~s}$ nas bandas de oitavas de frequências centrais $500,1.000$ e $2.000 \mathrm{~Hz}$. 


\section{Tempo de decaimento inicial (EDT - Early Decay Time)}

O parâmetro EDT (Early Decay Time - tempo de decaimento inicial) nada mais é do que uma medida do tempo de reverberação $\left(\mathrm{T}_{30}\right)$, porém analisada somente a parte inicial da taxa de decaimento de nível de pressão sonora dentro da sala, que é entre 0 e -10 dB (BRANDÃO, 2016; ROSSING, 2007). Ou seja, é o tempo necessário para o decaimento energético nos primeiros $10 \mathrm{~dB}$, a partir do estado estacionário, uma vez cessada a fonte de energia sonora. Um decaimento inicial rápido é interpretado pelo cérebro humano como se o tempo de reverberação de um ambiente fosse curto. Para ambientes em que a fala deve ser privilegiada, deseja-se que esta tenha intimidade - parâmetro subjetivo relacionado ao EDT que promove a sensação de que a sala possui um volume menor do que seu volume real. Os valores de EDT possuem comportamento semelhante aos encontrados para tempo de reverberação. Segundo Mehta, Johnson e Rocafort (1999), o valor de EDT adequado é o valor de EDT multiplicado por 6 e então comparado com o tempo de reverberação adequado para o ambiente em questão.

\section{Definição (D50)}

A definição é um parâmetro acústico objetivo que mede, em escala linear, a razão entre a energia contida nas primeiras reflexões e a energia total da resposta ao impulso (BRANDÃO, 2016; ROSSING, 2007). Baseiase na interferência das primeiras reflexões (reflexões que atingem o receptor até $50 \mathrm{~ms}$ ) no som direto, sendo consideradas reflexões úteis, por se somarem ao som direto, contribuindo para a inteligibilidade da palavra. Reflexões tardias são percebidas subjetivamente como efeitos prejudiciais introduzidos pela sala, que se manifestam como reverberação e, no caso de reflexões isoladas, como ecos. Existe um consenso entre vários autores de que resultados de definição acima de 0,50 para todas as bandas de frequência são considerados aceitáveis para diversos tipos de uso de salas (BERANEK, 2004; BRANDÃO, 2016; LONG, 2014; MEHTA; JOHNSON; ROCAFORT, 1999).

\section{Clareza (C50)}

A clareza é um parâmetro acústico objetivo que mede, em escala decibel, a razão entre a energia contida nas primeiras reflexões e a energia contida na cauda reverberante (energia restante da resposta impulsiva), estando associada à sensação subjetiva de distinguir sons em sequência (BRANDÃO, 2016; ROSSING, 2007). O sistema auditivo integra o som direto quando as primeiras reflexões chegam dentro de $50 \mathrm{~ms}$ ou 80 ms. Para isso, a clareza mede o quanto essas reflexões interferem no som direto. Para uma energia elevada, o som direto é amplificado e a cauda reverberante não é tão perceptível, e quando a energia é pequena, a cauda reverberante é mais perceptível, assim mascarando o som. Normalmente são utilizados como parâmetros de clareza o $\mathrm{C}_{50}$ e o $\mathrm{C}_{80}$, descrevendo o limite entre as primeiras reflexões e as caudas reverberantes de $50 \mathrm{~ms}$ e $80 \mathrm{~ms}$, respectivamente. Neste artigo, considera-se o $\mathrm{C}_{50}$, pois é empregado para espaços onde a fala é prioridade. $\mathrm{O}$ valor de $\mathrm{C}_{50}$ pode ser relacionado com o de $\mathrm{D}_{50}$, de acordo com a Equaçãp 1 (BRANDÃO, 2016). Portanto, como a definição deve possuir valores acima de 0,50 , a clareza deve possuir valores acima de 0 (zero).

$C_{50}=10 \log \left(\frac{D_{50}}{1-D_{50}}\right) d B$

Eq. 1

\section{Diferença mínima perceptível (JND)}

Em acústica de salas, uma forma de se avaliar a qualidade de um modelo de simulação computacional consiste em verificar se os resultados simulados estão dentro das faixas de JND obtidas a partir dos resultados medidos experimentalmente. Para Brandão (2016), a JND consiste na menor variação no valor do parâmetro que um ser humano médio pode perceber. A NBR ISO 3382-2 (ABNT, 2017) fornece a JND de vários parâmetros normalmente utilizados em acústica de salas. A JND pode fornecer informações importantes relacionadas à coerência do modelo virtual quando feita a comparação entre os resultados das simulações e os experimentais. Recomenda-se que a diferença entre esses valores esteja no intervalo de até 1 JND. Contudo, Vörlander (1995) menciona que podem ser tolerados desvios de até 2 JND.

\section{RaSTI (índice rápido de transmissão da fala)}

O parâmetro RaSTI é uma versão simplificada do parâmetro STI (Speech Transmission Index - índice de transmissão da fala), e tem por objetivo quantificar a inteligibilidade da palavra em ambientes fechados. Seus valores variam entre 0 (inteligibilidade nula) e 1 (inteligibilidade perfeita). Portanto, resumidamente, pode-se dizer que este índice indica a percentagem de sílabas realmente compreendidas em um discurso 
(MATEUS et al., 2008). O valor recomendado para este parâmetro, tendo-se como referência o ambiente analisado, deve ser o maior possível (na escala 0 a 1 ) e não inferior a 0,65 .

\section{Determinação dos parâmetros acústicos}

O software utilizado para a determinação dos parâmetros acústicos anteriormente mencionados, de forma experimental, foi o DIRAC 4.0, o qual se baseia na obtenção das IRFs do sistema sob investigação. A partir das IRFs, todos os parâmetros acústicos definidos pela norma NBR ISO 3382-2 (ABNT, 2017) são obtidos diretamente.

O sinal utilizado para determinar os parâmetros da sala foi o sinal MLS (Maximum Lenght Sequence). A utilização desse sinal requer algumas precauções como, por exemplo, o sistema sob teste deve ser linear e invariante no tempo, o tempo de duração do sinal MLS tem de ser maior do que o da resposta impulsiva do sistema ou, pelo menos, ter a mesma duração. Caso contrário, algumas partes da resposta computada serão perdidas. Para realizar as medições foram utilizados os seguintes equipamentos: placa de aquisição de áudio $M$ AUDIO (ver Figura 7a), um microfone omnidirecional Earthworks tipo TC25 (ver Figura 7b) com faixa de frequência de atuação de $9 \mathrm{~Hz}$ a $25 \mathrm{kHz}$ e uma fonte sonora omnidirecional B\&K tipo 4296 (ver Figura $7 \mathrm{c})$.

\section{Resultados e discussões}

\section{Coeficientes de absorção sonora de painéis absorvedores de fibra de açaí}

Para a obtenção dos coeficientes de absorção sonora dos painéis absorvedores de fibra de açaí, foi utilizada a seguinte infraestrutura: software LabshopView versão 12.5.0, minicâmara reverberante, analisador de sinais (PULSE) B\&K 3560C, medidor de nível sonoro 01dB - Metravib, Blue Solo 01, microfone GRAS, MCE 212 e microfone B\&K tipo 4942-A-021 para campo difuso, fonte sonora B\&K tipo 4224, alto-falante Selenium modelo MD BASS 6MB1 de 15" de diâmetro, termohigrômetro digital, amplificador, microcomputador (notebook), suportes para microfones, cabos de conexão (BNC, RJ45, Speakon), extensões elétricas, painéis de fibra de açaí e calibrador sonoro B\&K 4231.

Como os princípios válidos para câmaras em escala real se aplicam para câmaras em escala reduzida, como o princípio da reciprocidade e do campo difuso, foi utilizada a minicâmara reverberante descrita na seção Câmara reverberante utilizadas com o objetivo de se obter o coeficiente de absorção sonora dos painéis de açaí, utilizando o método de interrupção do ruído, que consiste em excitar acusticamente a câmara com ruído de banda larga, para assim se obterem as curvas de decaimento através do registro direto do decaimento do nível de pressão sonora.

As medições foram executadas e cumpridas conforme a norma ISO 354 (INTERNATIONAL..., 2003), que estabelece uma série de exigências e procedimentos a serem seguidos, como: número mínimo de medições necessárias para cada banda de frequência; diferença entre o nível de ruído residual e o nível de pressão sonora (NPS) da fonte seja de pelo menos $15 \mathrm{~dB}$ nas bandas de um terço de oitava; a absorção sonora das superfícies da câmara deve apresentar valores pequenos, não apresentando picos ou vales divergindo mais do que $15 \%$ da média de dois valores adjacentes em bandas de terço de oitava; e, por fim, a medição da temperatura e da umidade relativa do ambiente de ensaio. Os valores dos coeficientes de absorção sonora obtidos para o painel de fibra de açaí com $30 \mathrm{~mm}$ de espessura são listados na Tabela 1.

Embora apresente valores baixos nas frequências graves (até $500 \mathrm{~Hz}$ ), o material analisado se comporta como um bom absorvedor acústico, considerando que acima de $2.000 \mathrm{~Hz}$ a absorção sonora é superior a $80 \%$.

\section{Resultados de medição de parâmetros acústicos de uma sala de aula}

O ambiente analisado foi uma sala de aula de uma instituição de ensino superior. As medições foram realizadas fora dos horários de aula, para que o ruído ambiente não comprometesse as medições. A sala conta com carteiras (para alunos e professor), mesa e porta de madeira, janelas de vidro, quadro magnético, aparelhos de ar condicionado, e um armário para retroprojetor, apresentando volume interno de $136 \mathrm{~m}$, em um formato retangular de dimensões $6,25 \times 8,00 \times 2,72 \mathrm{~m}$. Esse ambiente é utilizado para aulas, apresentação de trabalhos, seminários e palestras, sendo, portanto, um ambiente em que a fala deve ser privilegiada, isto é, deve ter maximizada a sua inteligibilidade.

52 Bastos, L. P.; Lima, L. da C.; Santos, G. B.; Melo, G. da S. V. de; Mesquita, A. L. A. 
De acordo a norma NBR ISO 3382-2 (ABNT, 2017), foram analisados o tempo de reverberação $\left(\mathrm{T}_{30}\right)$, o tempo de decaimento inicial (EDT), a definição $\left(\mathrm{D}_{50}\right)$, a clareza $\left(\mathrm{C}_{50}\right)$ e o índice rápido de transmissão da fala (RaSTI), para cada banda de oitava entre $125 \mathrm{~Hz}$ e $8 \mathrm{kHz}$. A distribuição do nível de pressão sonora do ambiente não foi analisada devido ao tamanho reduzido da sala.

Foram realizadas as medições na sala de aula, sem e com audiência, conforme as Figura 8a e 8b, respectivamente. Nas medições, foram utilizadas duas posições diferentes de fonte e seis posições de microfone para cada uma destas duas posições, tanto nas medições da sala sem audiência quanto na presença dela, totalizando, assim, 24 medições, número maior que o mínimo de medições sugerido pela norma NBR ISO 3382-2 (ABNT, 2017). As seis posições de microfone se mantiveram idênticas em cada uma das posições de fonte nos casos sem e com audiência.

Ressalta-se que para a condição de ocupação (audiência) no experimento foram seguidas as indicações da norma NBR ISO 3382-2 (ABNT, 2017), que prescreve um mínimo de 50\% de ocupação das cadeiras, para assim promover diferenças perceptíveis em qualquer parâmetro analisado. Os resultados obtidos para as configurações descritas nas Figuras $8 \mathrm{a}$ e $8 \mathrm{~b}$ são mostrados na Tabela 2. De acordo com os resultados, verifica-se que a sala é reverberante, mesmo com a ocupação de $50 \%$ das 30 cadeiras da sala de aula. Portanto, a sala de aula necessita de condicionamento acústico.

Figura 7 - Equipamentos utilizados para determinação dos parâmetros acústicos: (a) sistema de aquisição de dados, (b) microfone omnidirecional e (c) fonte sonora

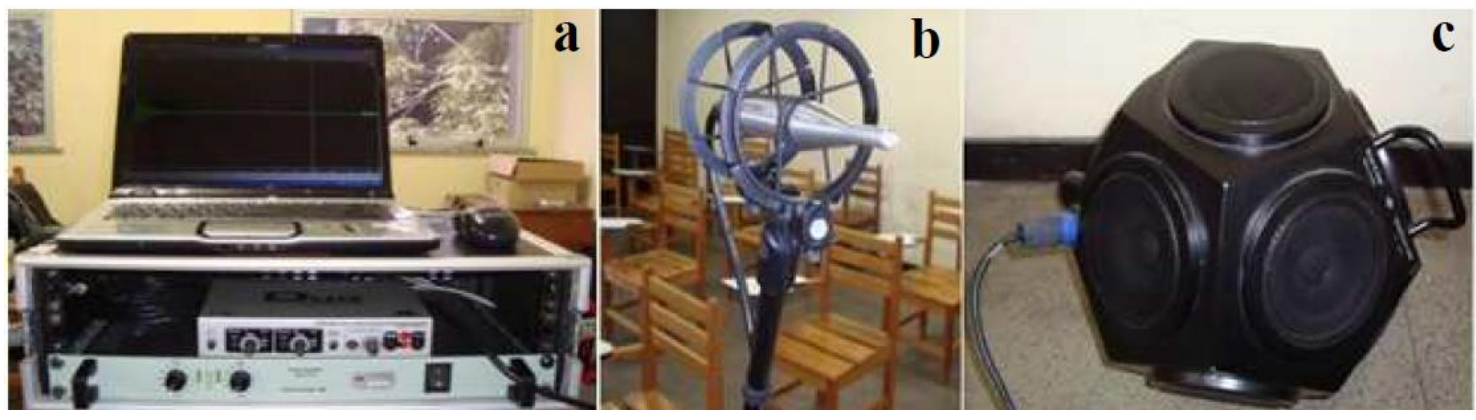

Fonte: Bastos (2009).

Tabela 1 - Coeficientes de absorção sonora do painel de fibra de açaí por banda de oitava

Coeficiente de absorção sonora do açaí

\begin{tabular}{c|c|c|c|c|c}
\hline $125 \mathrm{~Hz}$ & $250 \mathrm{~Hz}$ & $500 \mathrm{~Hz}$ & $1.000 \mathrm{~Hz}$ & $2.000 \mathrm{~Hz}$ & $4.000 \mathrm{~Hz}$ \\
\hline 0,33 & 0,18 & 0,36 & 0,56 & 0,80 & 0,87 \\
\hline
\end{tabular}

Figura 8 - Sala analisada durante medição de tempo de reverberação (a) sem audiência e (b) com audiência
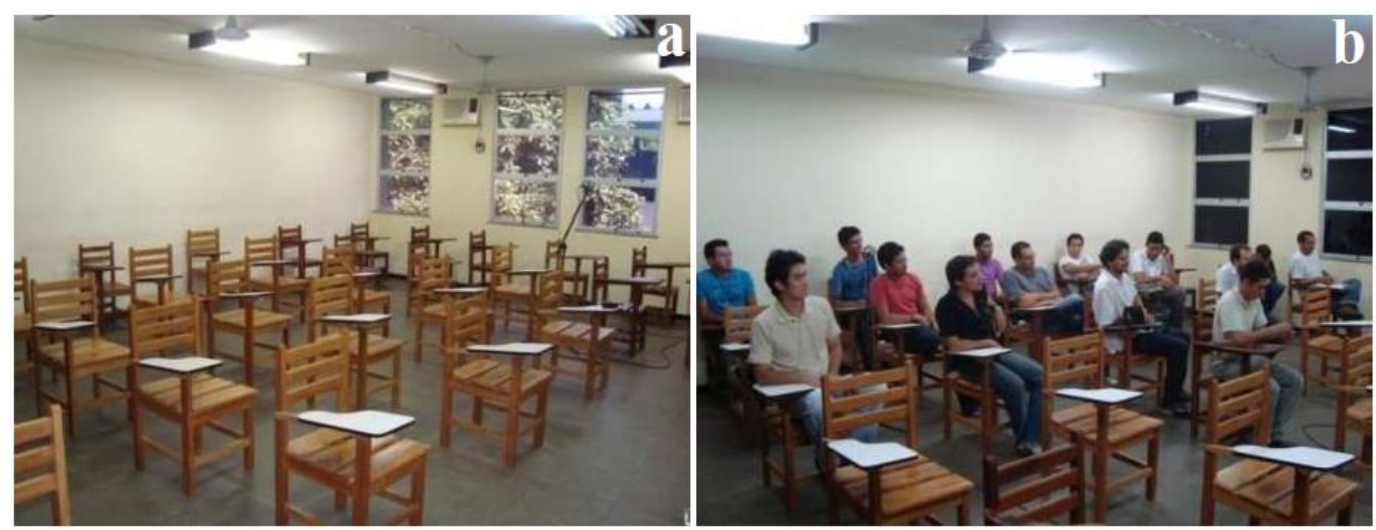

Fonte: Bastos (2009). 
Tabela 2 - Valores experimentais dos parâmetros acústicos da sala sem e com audiência

\begin{tabular}{|c|c|c|c|c|c|c|c|c|}
\hline Frequência & \multicolumn{4}{|c|}{ SEM AUDIÊNCIA } & \multicolumn{4}{|c|}{ COM AUDIÊNCIA } \\
\hline$(\mathbf{H z})$ & TR (s) & EDT (s) & $\mathbf{D}_{50}$ & RaSTI & TR (s) & EDT (s) & $\mathbf{D}_{50}$ & RaSTI \\
\hline 125 & 1,70 & 1,94 & 0,37 & & 1,73 & 1,61 & 0,35 & \\
\hline 250 & 1,60 & 1,87 & 0,35 & & 1,40 & 1,47 & 0,42 & \\
\hline 500 & 1,69 & 2,06 & 0,27 & 0,44 & 1,07 & 1,34 & 0,40 & 0,54 \\
\hline 1.000 & 1,58 & 1,99 & 0,28 & A & 0,94 & 1,17 & 0,43 & A \\
\hline 2.000 & 1,36 & 1,69 & 0,37 & 0,48 & 0,80 & 0,97 & 0,50 & 0,58 \\
\hline 4.000 & 1,14 & 1,34 & 0,44 & & 0,71 & 0,85 & 0,57 & \\
\hline 8.000 & 0,78 & 0,85 & 0,59 & & 0,62 & 0,60 & 0,69 & \\
\hline
\end{tabular}

\section{Análise numérica para melhoramento da inteligibilidade da fala}

A referida sala foi representada por um modelo geométrico virtual, desenvolvido no software SketchUp 2019 e importado para o software ODEON Room Acoustics 12.12 Combined, respeitando as recomendações apresentadas no manual do usuário, com relação aos detalhes das superfícies da sala e dos objetos em seu interior. A cada superfície foi atribuído um valor de coeficiente de absorção sonora e, opcionalmente, um valor de coeficiente de espalhamento, conforme suas reais características. Os dados de coeficiente de absorção utilizados foram usados de acordo com Vörlander (2008), Christensen et al. (2014) e a biblioteca global do ODEON 12.12 Combined em bandas de oitava de 63 a $8.000 \mathrm{~Hz}$.

A Figura 9 apresenta a vista isométrica do modelo geométrico, apresentando a origem do sistema de coordenadas cartesianas, correspondente ao adotado nas medições experimentais, facilitando o posicionamento da audiência, dos objetos, das fontes e dos receptores no interior do modelo.

Foram utilizados os seguintes materiais da biblioteca do ODEON 12.12 Combined para as superfícies do modelo: 102 - Smooth Concrete, Painted or Glazed; 103 - Concrete Block, Painted; 3068 - Plywood Paneling, $1 \mathrm{~cm}$ Thick; 5000 - Steel Trapez Profile; 6000 - Linoleum or Vinyl Stuck to Concrete; 10.006 Glass, Ordinary Window Glass; 10.007 - Solid Wooden Door. Para o quadro da sala de aula foram usadas as informações encontradas em Christensen, Koutsouris e Rindel (2014). Para cadeiras e alunos foram usados os dados encontrados em Vörlander (2008), em que o autor apresenta os coeficientes de absorção sonora mínimos e máximos, típicos para um tipo de audiência semelhante à condição dos alunos no interior da sala (pessoa sentada em grupo).

Para a etapa de calibração do modelo, os coeficientes de absorção sonora dos materiais e alunos foram ajustados (dentro da faixa permissível) para que houvesse a maior aproximação dos dados numéricos com os resultados medidos.

A Figura 10 apresenta, respectivamente, as curvas de calibração do modelo numérico para EDT e $\mathrm{D}_{50}$, a partir dos resultados experimentais para a sala sem audiência. Os resultados da banda de oitava de $125 \mathrm{~Hz}$ não são apresentados em virtude de estes não serem tão confiáveis nessa faixa com a aplicação da acústica geométrica e como o estudo utiliza a acústica geométrica é necessário estabelecer a frequência de corte para delimitar a validade do método, denominada frequência de Schroeder. Para a sala de aula em questão, essa frequência é de $215,6 \mathrm{~Hz}$.

Foi utilizado o parâmetro JND para auxiliar a calibração do modelo, pois é a menor variação que um ser humano pode perceber para cada um dos parâmetros. Baseado na norma NBR ISO 3382-2 (ABNT, 2017), os resultados das simulações comparados aos das medições experimentais in situ devem estar dentro do intervalo JND. Contudo, Vörlander (1995) cita que podem ser tolerados desvios de até 2 JND.

Conforme a Figura 10, os valores médios de EDT estão dentro da faixa de 1 JND para bandas de 500 a 2.000 $\mathrm{Hz}$, tendo pequenos desvios em outras bandas, sem ultrapassar o limite tolerável de 2 JND. Para o parâmetro $\mathrm{D}_{50}$, também sem audiência, pode ser observado que os resultados permaneceram quase todos dentro da faixa de $1 \mathrm{JND}$, exceto para a banda de $1.000 \mathrm{~Hz}$. Portanto, o modelo foi validado para os parâmetros EDT e $\mathrm{D}_{50}$ por estar completamente dentro da faixa tolerável de 2 JND. Assim, considera-se o modelo validado para a situação sem audiência.

Foi realizada também a validação do modelo para a sala com audiência para os mesmos parâmetros acústicos da análise sem audiência, conforme a Figura 11. Na análise dos parâmetros EDT e D50, é possível observar que os valores se mantiveram dentro da faixa de $1 \mathrm{JND}$, exceto para EDT em $1.000 \mathrm{~Hz}$, mas ainda dentro da faixa de 2 JND. Portanto, o modelo foi validado também para a condição com audiência.

54 Bastos, L. P.; Lima, L. da C.; Santos, G. B.; Melo, G. da S. V. de; Mesquita, A. L. A. 
Figura 9 - Modelo geométrico da sala construído no SketchUp 2019 em vista isométrica

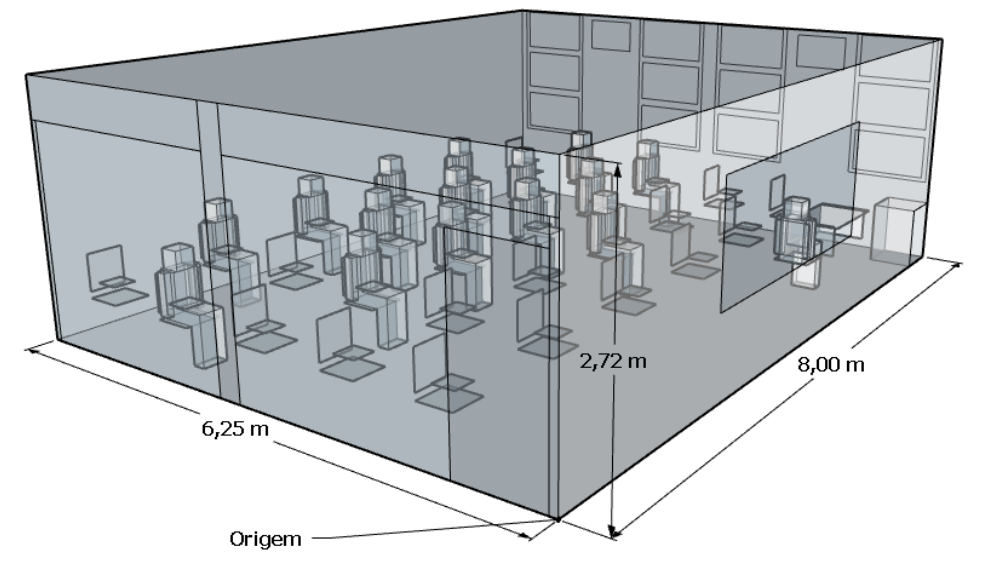

Figura 10 - Gráfico comparativo entre os valores médios de EDT e D50 medidos e simulados para a sala sem audiência
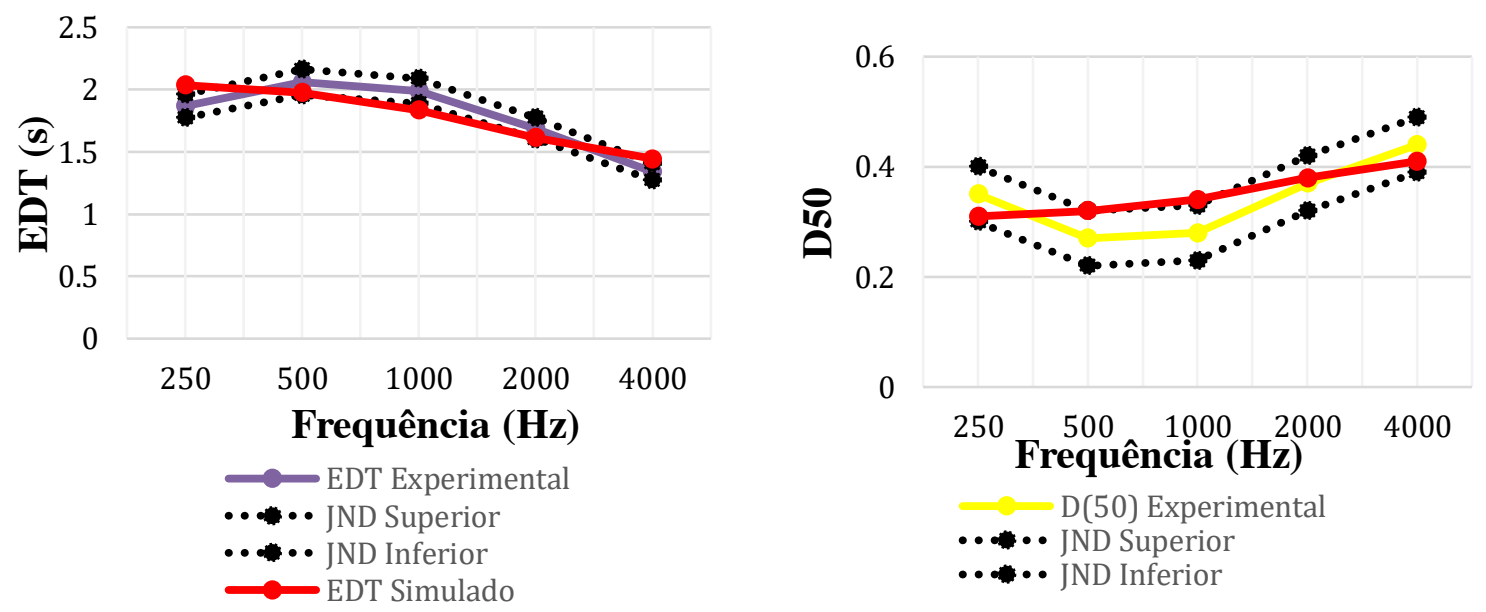

Figura 11 - Gráfico comparativo entre os valores médios de EDT e D50 medidos e simulados para a sala com audiência
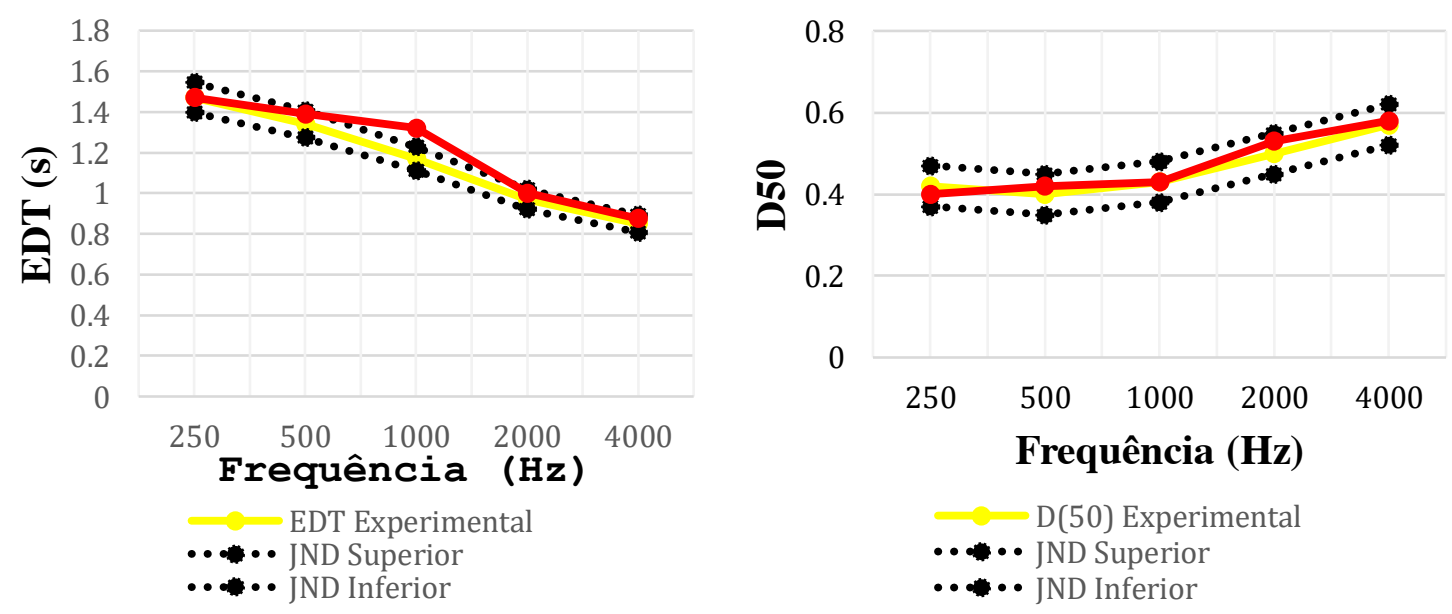

A Tabela 3 apresenta os coeficientes de absorção sonora dos elementos utilizados nas simulações após a calibração do modelo da sala. 
Tabela 3 - Coeficientes de absorção sonora das superfícies dos modelos numéricos da sala

\begin{tabular}{c|c|c|c|c|c|c}
\hline \multirow{2}{*}{ Objeto } & \multicolumn{5}{|c}{ Coeficientes de absorção sonora dos materiais } \\
\cline { 2 - 6 } & $\mathbf{1 2 5}$ & $\mathbf{2 5 0}$ & $\mathbf{5 0 0}$ & $\mathbf{1 . 0 0 0}$ & $\mathbf{2 . 0 0 0}$ & $\mathbf{4 . 0 0 0}$ \\
\hline Armário & 0,28 & 0,22 & 0,17 & 0,09 & 0,10 & 0,11 \\
\hline Porta de madeira & 0,14 & 0,10 & 0,06 & 0,08 & 0,10 & 0,10 \\
\hline Janelas de vidro & 0,35 & 0,25 & 0,18 & 0,12 & 0,07 & 0,04 \\
\hline Cadeiras & 0,05 & 0,05 & 0,08 & 0,10 & 0,10 & 0,10 \\
\hline Mesa de madeira & 0,28 & 0,22 & 0,17 & 0,09 & 0,10 & 0,11 \\
\hline Paredes de reboco & 0,01 & 0,02 & 0,02 & 0,03 & 0,03 & 0,04 \\
\hline Quadro & 0,01 & 0,01 & 0,03 & 0,02 & 0,01 & 0,08 \\
\hline Piso & 0,01 & 0,01 & 0,01 & 0,02 & 0,02 & 0,02 \\
\hline Teto & 0,10 & 0,05 & 0,06 & 0,07 & 0,09 & 0,08 \\
\hline Painéis de vidro & 0,35 & 0,25 & 0,18 & 0,12 & 0,07 & 0,04 \\
\hline Esquadrias de alumínio & 0,30 & 0,25 & 0,20 & 0,10 & 0,10 & 0,15 \\
\hline Ar condicionado & 0,02 & 0,02 & 0,03 & 0,04 & 0,04 & 0,05 \\
\hline Alunos sentados & 0,09 & 0,25 & 0,29 & 0,29 & 0,37 & 0,54 \\
\hline Parede de madeira & 0,28 & 0,22 & 0,17 & 0,09 & 0,10 & 0,11 \\
\hline Painéis de açaí (30 mm) & 0,54 & 0,37 & 0,48 & 0,81 & 0,79 & 0,87 \\
\hline Poliuretano (25 mm) & 0,04 & 0,15 & 0,49 & 0,73 & 0,83 & 0,90 \\
\hline
\end{tabular}

Com o modelo validado, o qual reproduziu resultados satisfatórios e condizentes com as medições experimentais, foram inseridos na sala painéis de fibra de açaí em 5 diferentes configurações, conforme a Figura 12, e seus resultados foram analisados a fim de verificar qual a melhor configuração. De forma a comparar o desempenho do painel de açaí, foi também feita, para a configuração 1, uma análise dos parâmetros acústicos usando painéis de espuma de poliuretano disponível comercialmente (OWA..., 2019) e os resultados comparados. Contudo, ressalta-se que a espessura do painel de espuma de poliuretano é de 25 $\mathrm{mm}$ (5 $\mathrm{mm}$ a menos do que os painéis de açaí) em virtude de ser o que mais se adequou à espessura dos painéis de fibra do açaí.

As 5 configurações de posicionamento e a quantidade de área dos painéis foram fundamentadas nos trabalhos de Cucharero e Hänninen e Lokki (2019) e Sala e Viljanen (1995). Em seus estudos, os resultados mostraram que o posicionamento de absorvedores nos cantos do teto ou das paredes diminuiu a absorção quando o campo sonoro era aproximadamente difuso, o que fornece uma base para esse estudo de caso, por possuir superfícies reflexivas. Além disso, é recomendado que o material absorvedor cubra uma área de $30 \%$ do teto, associada com as paredes laterais, frontal e traseira. Sala e Viljanen (1995) demostraram que, em salas de aula, os absorvedores devem ser colocados em pelo menos duas superfícies diferentes para maximizar a inteligibilidade da fala, sendo recomendados o teto e a parede traseira.

A área total de paredes e teto que compõem a sala soma 127,52 m . Para a escolha da colocação dos painéis, a área de cada configuração em porcentagem relativa à área do teto e das paredes foi de 30\% (38,26 m ), $20 \%(25,50 \mathrm{~m})$ e $15 \%(19,13 \mathrm{~m})$, respectivamente. Para as configurações que foram escolhidas somente uma superficie para a colocação dos painéis, os valores foram de 15,70\% $\left(20,02 \mathrm{~m}^{2}\right)$ e 4,30\% $\left(5,50 \mathrm{~m}^{2}\right)$. A Tabela 4 apresenta a porcentagem em área da região parede traseira e teto, na qual foi dividida a inserção dos painéis de fibra do açaí.

Os resultados dos parâmetros EDT, $\mathrm{T}_{30}, \mathrm{D}_{50}$ e $\mathrm{C}_{50}$ nas 5 configurações para sala com audiência e para sala sem painel são apresentados em bandas de oitava de 250 a $4.000 \mathrm{~Hz}$ nas Figuras 13, 14, 15 e 16, respectivamente. Os resultados do parâmetro RaSTI são apresentados na Tabela 5.

Nas Figuras 13 e 14 percebe-se que a configuração \#1 apresenta os melhores valores de EDT e $\mathrm{T}_{30}$, sendo seguida da configuração \#2. As configurações \#3 e \#4 apresentam valores quase idênticos desses parâmetros acústicos ao longo de toda a faixa de frequência analisada. A configuração \#5 foi a que apresentou valores menos satisfatórios dentre as configurações. Mas, ainda assim, nesta última configuração, os parâmetros acústicos tornam-se melhores do que na sala sem painéis.

Em relação ao parâmetro RaSTI, os melhores desempenhos foram as configurações \#1, \#2, \#3 e \#4, nesta ordem. A configuração \#5, como ficou com um valor abaixo de 0,65 , não apresentou bom desempenho, corroborando com os prévios resultados de EDT e $\mathrm{T}_{30}$. 
Figura 12 - Configurações propostas para a inserção dos painéis: (a) \#1, (b) \#2, (c) \#3, (d) \#4 e (e) \#5

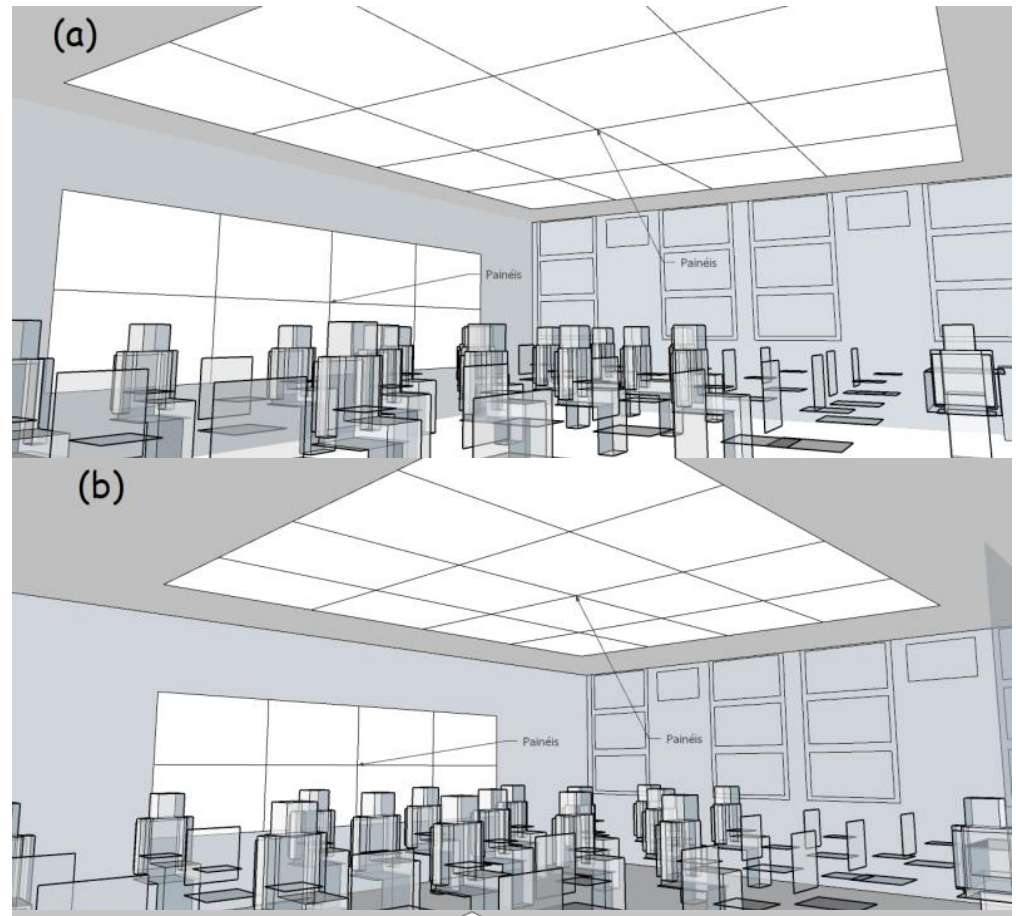

(c)

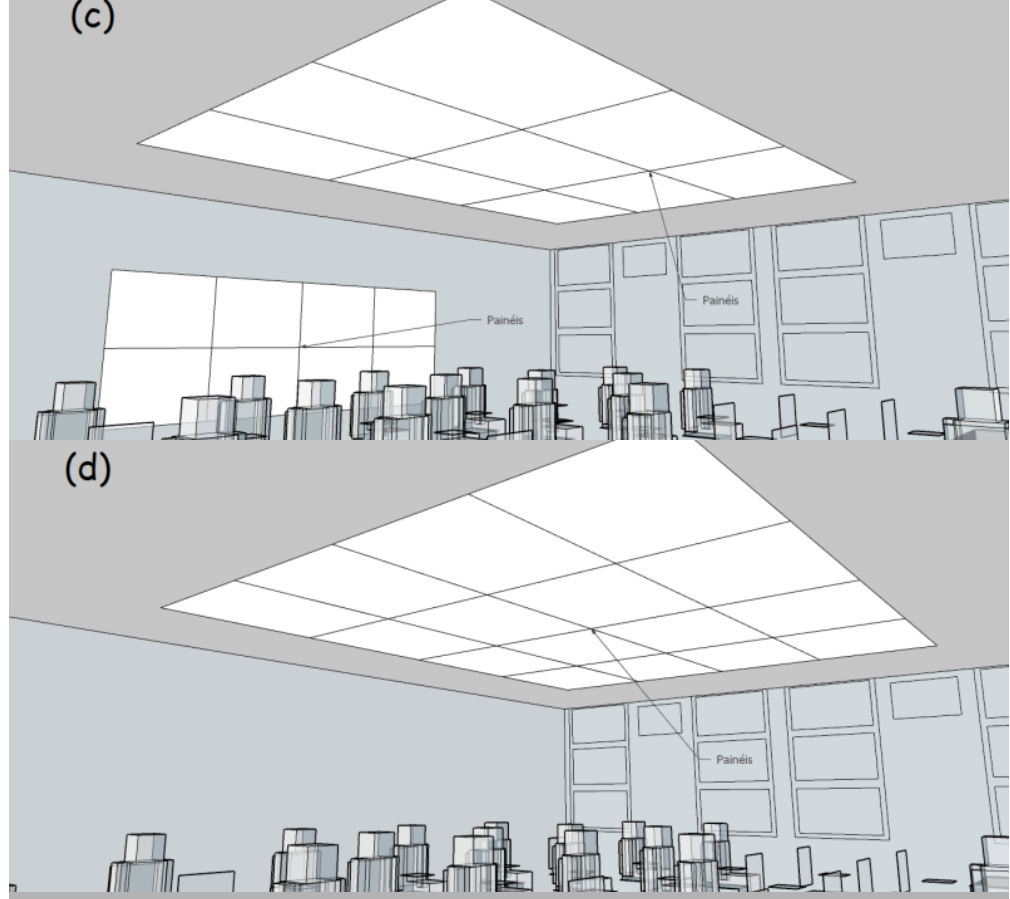

(e)

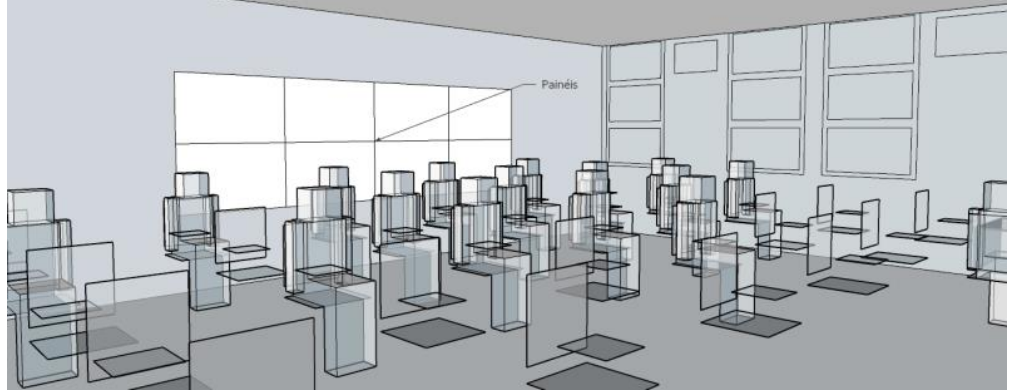


Tabela 4 - Área de absorção sonora das superfícies dos modelos numéricos da sala

\begin{tabular}{c|c|c|c}
\hline Configuração & $\begin{array}{c}\text { Fração de área de painel } \\
\text { em relação à área do teto e } \\
\text { das paredes }\end{array}$ & $\begin{array}{c}\text { Fração de área de painel } \\
\text { no teto em relação à área } \\
\text { do total de painel }\end{array}$ & $\begin{array}{c}\text { Fração de área de painel } \\
\text { na parede traseira em } \\
\text { relação à área de painel }\end{array}$ \\
\hline$\# 1$ & $30,00 \%$ & $78,40 \%$ & $21,60 \%$ \\
$\# 2$ & $20,00 \%$ & $78,40 \%$ & $21,60 \%$ \\
$\# 3$ & $15,00 \%$ & $75,30 \%$ & $24,70 \%$ \\
$\# 4$ & $15,70 \%$ & $100,00 \%$ & $0,00 \%$ \\
$\# 5$ & $4,30 \%$ & $0,00 \%$ & $100,00 \%$ \\
\hline
\end{tabular}

Figura 13 - Comparação do EDT nas 5 configurações de inserção do painel de açaí e sem painel

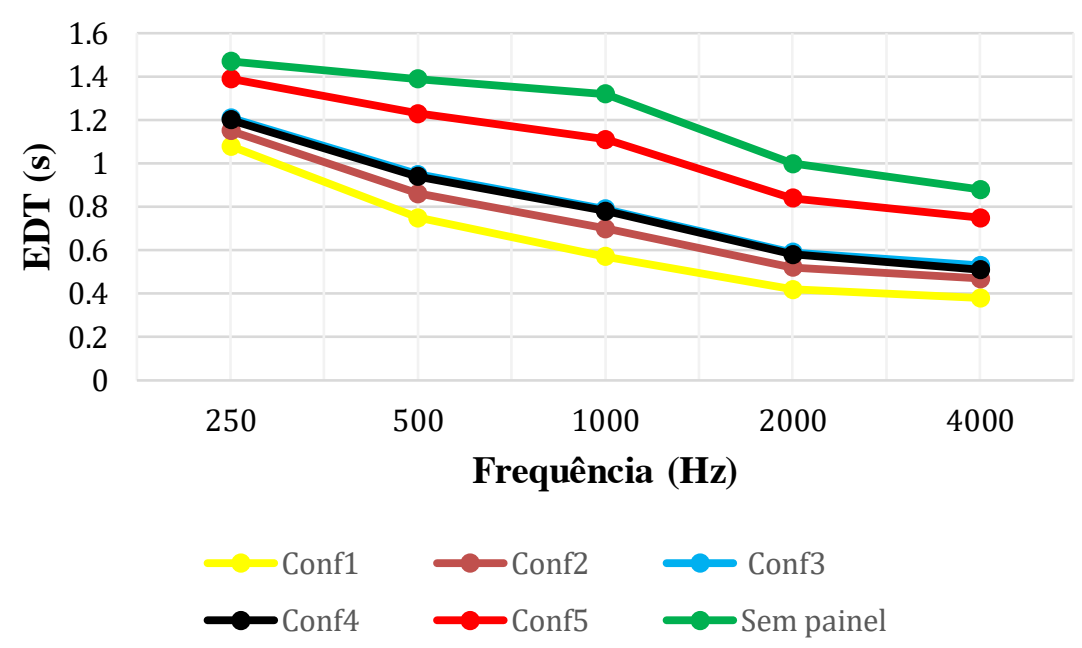

Figura 14 - Comparação do T30 nas 5 configurações de inserção do painel de açaí e sem painel

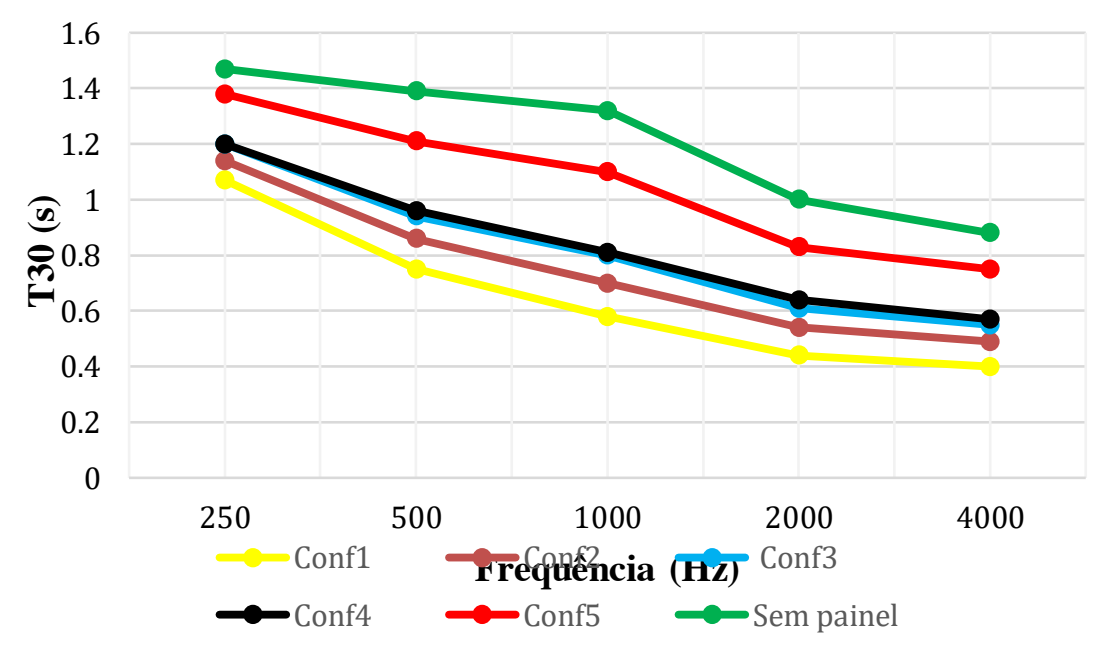

Tabela 5 - Comparação do RaSTI nas 5 configurações de inserção de painel de açaí

\begin{tabular}{c|c}
\hline Configuração & RaSTI \\
\hline$\# 1$ & 0,74 \\
$\# 2$ & 0,70 \\
$\# 3$ & 0,68 \\
$\# 4$ & 0,68 \\
$\# 5$ & 0,60 \\
\hline
\end{tabular}


De acordo com o gráfico da Figura 15, a configuração \#1 é que apresenta os melhores valores de definição, ou seja, valores acima de 0,5 em toda a faixa de frequência. A configuração \#2 também apresenta valores acima de 0,5 em praticamente todas as bandas de frequências, mas com valores inferiores à configuração \#1. Somente na frequência de $250 \mathrm{~Hz}$, o valor é exatamente igual a 0,5 para esta configuração \#2. Em seguida, as configurações \#3 e \#4 também apresentam bom desempenho nesse parâmetro, mas inferiores à configuração \#2. Ressalta-se que a configuração \#4 apresenta valores levemente superiores à configuração \#3. A configuração \#5 apresentou valores satisfatórios de definição a partir de $1.000 \mathrm{~Hz}$. Pelo gráfico, percebe-se o quanto a sala sem painéis possui baixo desempenho de definição.

Considerando que na literatura existe um consenso para valores ótimos de definição, devendo ser maiores que 0,5 e que há uma relação matemática entre os valores de definição e clareza, então foram substituídos os valores de definição da melhor configuração para então obter os melhores valores de clareza que estão no intervalo de 0 até a um valor pouco acima de $8 \mathrm{~dB}$. Foi identificado que a primeira configuração apresentou os melhores resultados, seguido das configurações \#2, \#4 e \#3, sendo essas duas últimas praticamente iguais.

No intuito de comparar o desempenho dos painéis de açaí com painéis comerciais de espuma de poliuretano, fez-se análise comparativa desses dois materiais na configuração \#1. Os resultados para EDT, T $30, \mathrm{D}_{50}$ e $\mathrm{C}_{50}$ são apresentados nas Figuras 17 e 18. Pode-se perceber que há praticamente os mesmos valores dos parâmetros para frequências a partir de $500 \mathrm{~Hz}$. Abaixo de $500 \mathrm{~Hz}$, a configuração com painéis de açaí apresenta um desempenho superior, sendo que são painéis um pouco mais espessos (diferença de $5 \mathrm{~mm}$ ) do que os painéis de poliuretano.

Figura 15 - Comparação do $D_{50}$ nas 5 configurações de inserção do painel de açaí e sem painel

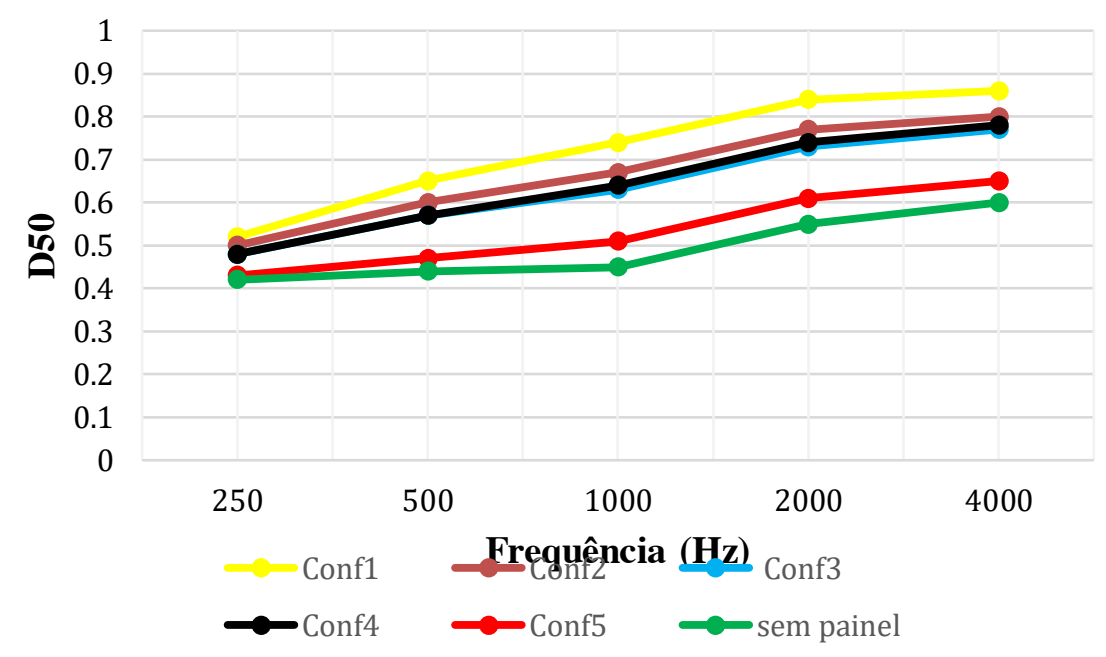

Figura 16 - Comparação do C50 nas 5 configurações de inserção do painel de açaí e sem painel

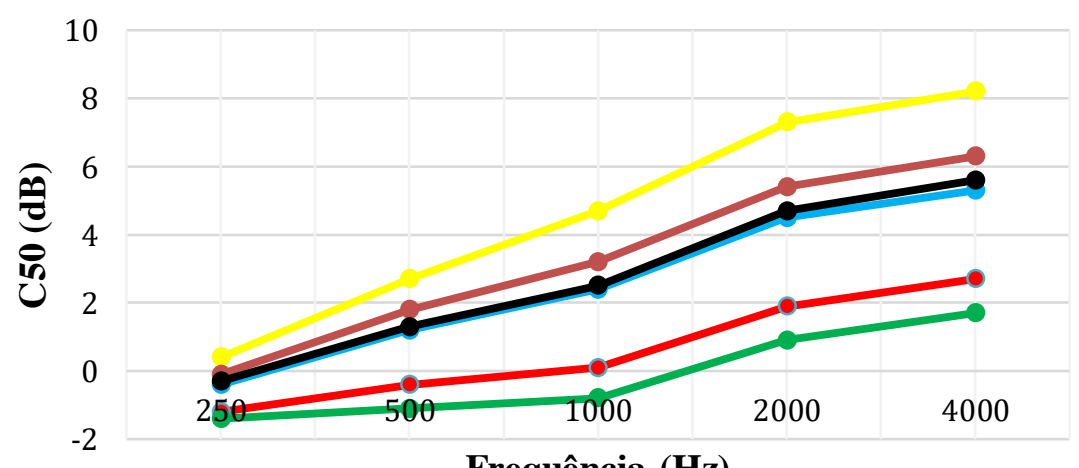

Frequência (Hz)

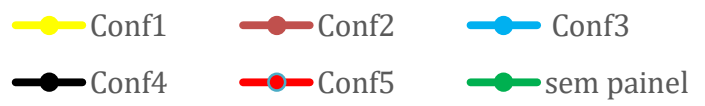


Figura 17 - Comparação dos parâmetros EDT e tempo de reverberação para diferentes materiais dos painéis na configuração \#1
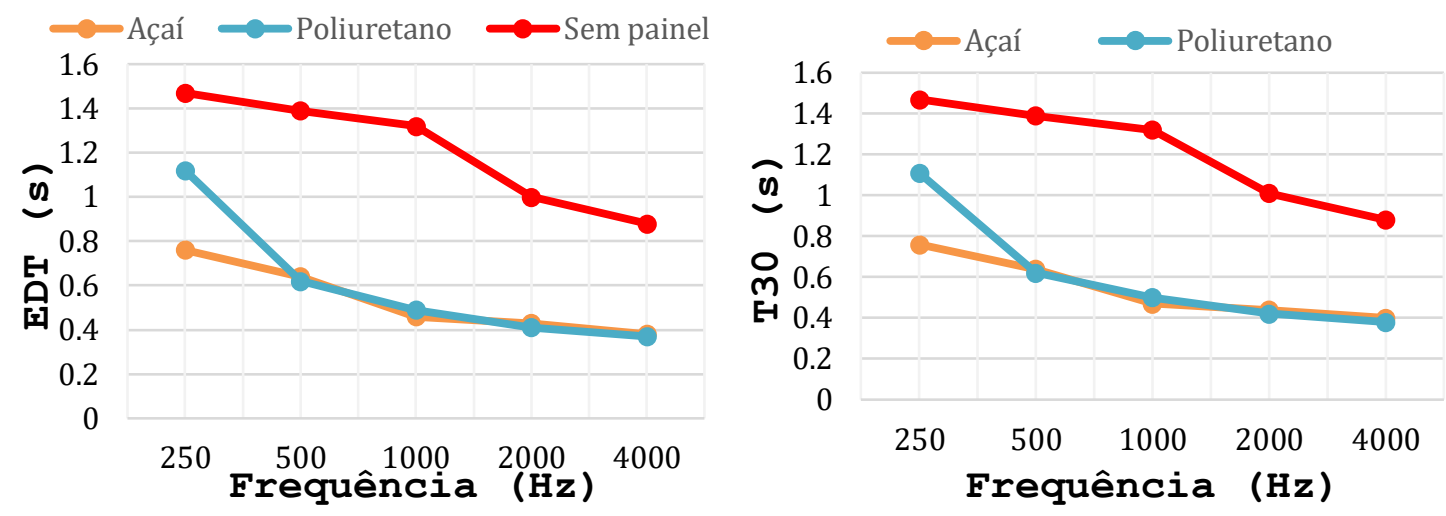

Figura 18 - Comparação dos parâmetros definição e clareza para diferentes materiais dos painéis na configuração \#1
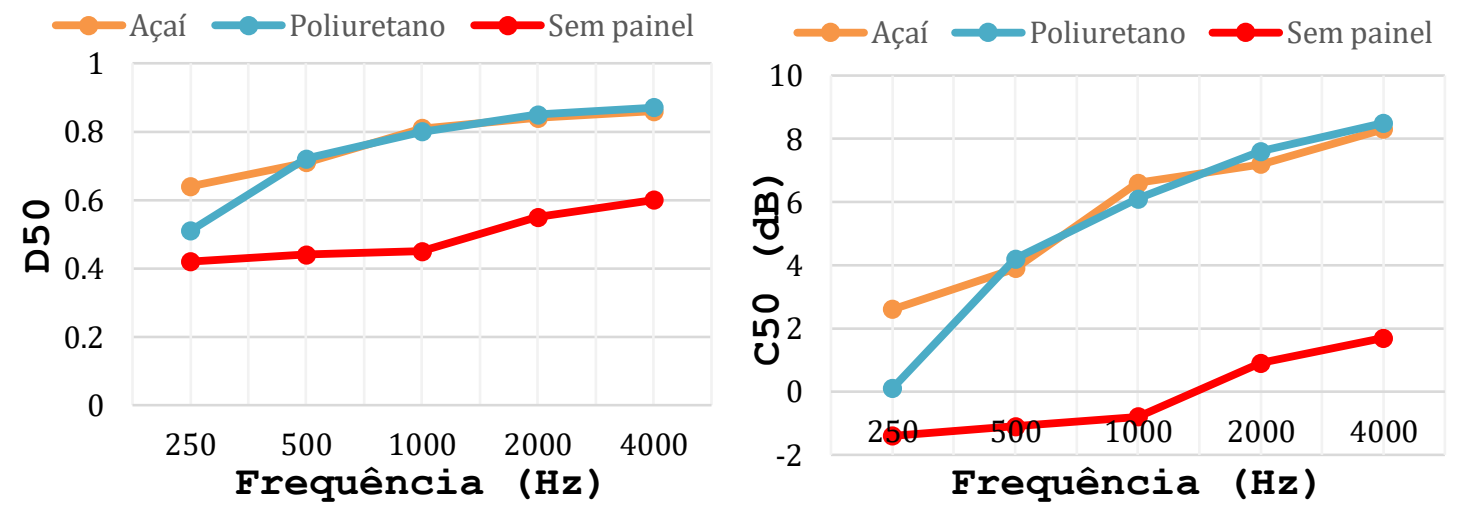

\section{Conclusão}

Salas de aula bastantes reverberantes podem trazer sérias consequências tanto para os alunos quanto para os professores. Dessa forma, a proposta deste trabalho foi avaliar o potencial da aplicação de painéis absorventes acústicos, produzidos a partir da fibra do caroço do açaí, no condicionamento acústico de salas de aula reverberantes para melhorar a inteligibilidade da fala nesses ambientes.

Em um estudo de caso, uma sala de aula foi caracterizada como reverberante, por meio de medições dos parâmetros acústicos $\left(\mathrm{T}_{30}, \mathrm{EDT}, \mathrm{D}_{50}, \mathrm{C}_{50}\right.$ e RaSTI). Em seguida, um modelo numérico da sala foi validado (por meio dos parâmetros EDT e D50). Por último, foram aplicadas no modelo 5 configurações de painéis absorventes acústicos feitos com fibras de caroços de açaí. A configuração \#1 foi a que apresentou o melhor desempenho nos citados parâmetros acústicos. Contudo, em uma relação custo/benefício, as configurações \#2, \#3 e \#4 podem ser viáveis. Somente a configuração \#5 não apresentou bons valores dos parâmetros acústicos que mensuram a inteligibilidade da fala na referida sala de aula. Portanto, o uso de modelos numéricos é importante na avaliação prévia de uma disposição de painéis acústicos em um ambiente.

Na configuração \#1, foram também comparados valores dos parâmetros acústicos da sala usando painéis de fibra de açaí com valores usando painéis comerciais de poliuretano (menos espessos). Abaixo de $500 \mathrm{~Hz}$, os painéis de fibra de açaí apresentaram valores levemente superiores aos painéis de poliuretano. Acima de 500 $\mathrm{Hz}$, os resultados foram praticamente iguais. Portanto, os resultados das simulações indicam que os painéis de fibra de açaí podem ser uma solução bastante atrativa, aliando baixo custo e bom desempenho, além de fornecer uma solução ambientalmente sustentável, apontando uma destinação para o problema do descarte dos caroços do açaí usados na alimentação, principalmente na Região Norte do país.

É importante ressaltar que os coeficientes de absorção sonora dos painéis de fibra de açaí usados nas simulações numéricas foram obtidos a partir de medições experimentais em câmara reverberante em escala 
reduzida, que por sua vez apresentam resultados próximos aos resultados em câmara em escala real, como verificado em medições realizadas em outro material. Entretanto, a comprovação da avaliação desse bom potencial do painel de fibra do caroço de açaí será realizada experimentalmente em salas de aula após os coeficientes de absorção terem sido avaliados em câmara reverberante em escala real, o que é objeto de futura análise.

\section{Referências}

ANDRADE JUNIOR, F. C. P.; GUERRA, W. H. L. Desenvolvimento e validação de uma câmara reverberante em escala para determinação de propriedades acústicas de materiais. Tucuruí, 2018. Trabalho de Conclusão de Curso (Graduação em Engenharia Mecânica) - Universidade Federal do Pará, Tucuruí, 2018.

AMERICAN NATIONAL STANDARDS INSTITUTE. Standard 12.60: acoustical performance criteria, design requirements and guidelines for schools: part 1: permanent schools. Melville, 2010.

ASDRUBALI, F.; SCHIAVONIL, S.; HOROSHENKOV, K. V. A review of sustainable materials for acoustic applications. Building Acoustics, v. 19, n. 4, p. 283-312, 2012.

ASSOCIACÃO BRASILEIRA DE NORMAS TÉCNICAS. NBR ISO 3382-2: acústica: medição de parâmetros de acústica de salas: parte 2: tempo de reverberação em salas comuns. Rio de Janeiro, 2017.

BASTOS, L. P. Desenvolvimento e caracterização acústica de painéis multicamadas unifibras, multifibras e mesclados, fabricados a partir de fibras vegetais. Belém, 2009. 157 f. Dissertação (Mestrado em Engenharia Civil) - Universidade Federal do Pará, Belém, 2009.

BASTOS, L. P.; MELO, G. S. V.; SOEIRO, N. S. Panels manufactured from vegetable fibers: an alternative approach for controlling noises in indoor environments. Advances in Acoustics and Vibration, v. 2012, article ID 698737, 2012.

BERANEK, L. Concert halls and opera houses: music, acoustics, and achitecture. $2^{\text {nd }}$. ed. New York: Springer-Verlag, 2004.

BERARDI, U.; IANNACE, G. Acoustic characterization of natural fibers for sound absorption applications. Building and Environment, v. 94, p. 840-852, 2015.

BERTOLI, S. R. Avaliação do conforto acústico de prédios escolares da rede pública: o caso de Campinas. In: ENCONTRO NACIONAL, 6; ENCONTRO LATINO AMERICANO SOBRE CONFORTO NO AMBIENTE CONSTRUíDO, 3., Águas de São Pedro, 2001. Anais [...] Águas de São Pedro, 2001.

BISTAFA. S. R. Acústica aplicada ao controle do ruído. 2. ed. São Paulo: Blucher, 2011.

BRANDÃO, E. Acústica de salas: projeto e modelagem. São Paulo: Blucher, 2016.

CASTRO, K. J.; FONSECA, W. L. R. Avaliação da difusão sonora de uma câmara reverberante em escala reduzida a partir da utilização de diferentes geometrias e configurações de difusores sonoros. Tucuruí, 2019. Trabalho de Conclusão de Curso (Graduação em Engenharia Mecânica) - Universidade Federal do Pará, Tucuruí, 2019.

CHRISTENSEN, C. L.; KOUTSOURIS, G.; RINDEL, J. H. Estimating absorption of materials to match room model against existing room using a genetic algorithm. In: FORUM ACUSTICUM, Cracóvia, 2014. Proceedings [...] Cracóvia, 2014.

CORDEIRO, L. N. P. et al. Caracterização da cinza de caroço de açaí residual para adição ao concreto. Ambiente Construído, Porto Alegre, v. 19, n. 1, p. 45-55, jan./mar. 2019.

CORREA, B. A. et al. Reaproveitamento de resíduos orgânicos regionais agroindustriais da Amazônia tocantina como substratos alternativos na produção de mudas de alface. Revista Brasileira de Agropecuária Sustentável, v. 9, n. 1, p. 97-105, 2019.

CUCHARERO, J.; HÄNNINEN, T.; LOKKI, T. Influence of sound-absorbing material placement on room acoustical parameters. Acoustics, v. 1, n. 3, p. 644-660, 2019.

DREOSSI, R. C. F.; SANTOS, T. M. M. A interferência do ruído na aprendizagem. Revista Psicopedagogia, v. 2, n. 64, p. 38-47, 2004.

DURUP, N. et al. An investigation into relationships between classroom acoustic measurements and voice parameters of teachers. Building Acoustics, v. 22, n. 3/4, p. 225-241, 2015. 
ESCOBAR, V. G.; MORILLAS, J. M. B. Analysis of intelligibility and reverberation time recommendations in educational rooms. Applied Acoustics, v. 96, p. 1-10, 2015.

GERGES, S. N. Y. Ruídos: fundamentos e controle. 2 ed. Florianópolis: NR Editora, 2000.

GONÇALVES, V. S. B.; SILVA, L. B.; COUTINHO, A. S. Ruído como agente comprometedor da inteligibilidade de fala dos professores. Produção, v. 18, n. 3, p. 466-476, 2009.

INTERNATIONAL ORGANIZATION FOR STANDARDIZATION. ISO 354: acoustics: measurement of sound absorption in a reverberation room. Genebra, 2003.

LIMA, P. R.; VERGARA, E. F. Simulação acústica de uma sala multiuso para a prática musical: possibilidades de adaptação ao uso. Ambiente Construído, Porto Alegre, v. 18, n. 3, p. 161-173, jul./set. 2018.

LONG, M. Architectural acoustics. $2^{\text {nd }}$. ed. Boston: Academic Press, 2014.

MADBOULY, A. I. et al. Assessment model of classroom acoustics criteria for enhancing speech intelligibility and learning quality. Applied Acoustics, v. 114, p. 147-158, 2016.

MATEUS, D. et al. Avaliação dos parâmetros de qualidade sonora nas capelas da reconciliação no edifício da nova igreja do santuário de Fátima. In: ACÚSTICA 2008 - CONGRESSO IBÉRICO DE ACÚSTICA, 5., Coimbra, 2008. Anais [...] Coimbra, 2008.

MEHTA, M.; JOHNSON, J.; ROCAFORT, J. Architectural acoustics: principles and design. Colombus: Prentice Hall, 1999.

OWA SONEX BRASIL. Placa Acústica Sonex illtec Plano. 2019. Disponível em: https://owa.com.br. Acesso em: 29 mar. 2019.

PORTINHO, J. A.; ZIMMERMANN, L. V.; BRUCK, M. R. Efeitos benéficos do açaí. International Journal of Nutrology, v. 5, n. 1, p. 15-20, 2012.

RABELO, A. T. V. et al. Efeito das características acústicas de salas de aula na inteligibilidade de fala dos estudantes. CoDAS, v. 26, n. 5, p. 360-365, 2014.

RANTALA, L. M.; SALA, E. Effects of classroom acoustics on teachers' voices. Building Acoustics, v. 22, n. 3 e 4, p. 243-258, 2007.

ROSSING, T. Springer handbook of acoustics. New York: Springer-Verlag, 2007.

SALA, E.; VILJANEN, V. Improvement of acoustic conditions for speech communication in classrooms. Applied Acoustics, v. 45, p. 81-91, 1995.

SILVA, S. S.; SILVA, G. F.; CASTRO, D. F. Utilização de fibras do mesocarpo e caroço do açaí como componente de misturas areia-asfalto para a pavimentação na cidade de Manaus/AM. The Journal of Engineering and Exact Sciences, v. 3, n. 4, p. 627-633, 2016.

TANG, X.; YAN, X. Acoustic energy absorption properties of fibrous materials: a review. Composites Part A: Applied Science and Manufacturing, v. 101, p. 360-380, 2017.

TENENBAUM, R. A.; CAMILO, T. S. Método híbrido para simulação numérica de acústica de salas: teoria, implantação computacional e validação experimental. In: SEMINÁRIO MÚSICA CIÊNCIA TECNOLOGIA: ACÚSTICA MUSICAL, 1., São Paulo, 2004. Anais [...] São Paulo, 2004.

VERGARA, E. F.; MARROS, F.; PAUL, S. Caracterização da qualidade acústica de salas de aula para a prática e ensino musical. Ambiente Construído, Porto Alegre, v. 17, n. 1, p. 23-27, jan./mar. 2017.

VIEIRA, R. J. A. Desenvolvimento de painéis confeccionados a partir de fibras de coco para controle acústico de recintos. Belém, 2008. 262 f. Dissertação (Mestrado em Engenharia Mecânica) - Universidade Federal do Pará, Belém, 2008.

VORLÄNDER, M. Auralization: fundamentals of acoustics, modelling, simulation, algorithms and acoustic virtual reality. Berlin: Springer, 2008.

VORLÄNDER, M. International round robin on room acoustical computer simulations. In:

INTERNATIONAL CONGRESS ON ACOUSTICS, 15., Trondheim, 1995. Proceedings [...] Trondheim, 1995. 
VORLÄNDER, M.; BIETZ, H. Comparison of Methods for Measuring Reverberation Time. Acustica, v. 80, p. 205-215, 1994.

WECKNER, F. C. et al. Uso de caroço de açaí triturado fermentado, para a formulação de substratos para a produção de mudas de quiabo e tomate. Revista da Universidade Vale do Rio Verde, v. 14, n. 1, p. 700706, 2016.

YAMAGUCHI, K. K. L. et al. Amazon acai: chemistry and biological activities: a review. Food Chemistry, v. 179, p. 137-151, 2015.

\section{Leopoldo Pacheco Bastos}

Núcleo de Desenvolvimento Amazônico em Engenharia | Universidade Federal do Pará | Campus de Tucuruí |Tucuruí - PA - Brasil | CEP 68464-000 | Tel.: (91) 3201-7031 | E-mail: leopbastos@ufpa.br

\section{Lays da Cunha Lima}

Instituto de Tecnologia | Universidade Federal do Pará | Rua Augusto Corrêa, 01, Guamá | Belém - PA - Brasil | CEP 66075-110 | E-mail: lays.cunhalima@gmail.com

\section{Gabriel Brandão Santos}

Instituto de Tecnologia | Universidade Federal do Pará | E-mail: s.gabrielbrandao@gmail.com

\section{Gustavo da Silva Vieira de Melo}

Instituto de Tecnologia | Universidade Federal do Pará | Tel.: (91) 3201-7961 | E-mail: gmelo@ufpa.br

Alexandre Luiz Amarante Mesquita

Instituto de Tecnologia | Universidade Federal do Pará | Tel.: (91) 3201-7251 | E-mail: alexmesq@ufpa.br

\section{Ambiente Construído}

Revista da Associação Nacional de Tecnologia do Ambiente Construído

Av. Osvaldo Aranha, $99-3^{\circ}$ andar, Centro

Porto Alegre - RS - Brasil

CEP $90035-190$

Telefone: +55 (51) 3308-4084

www.seer.ufrgs.br/ambienteconstruido www.scielo.br/ac

E-mail: ambienteconstruido@ufrgs.br 